\title{
New Approaches to an Old Problem: Original Techniques in [FeFe]-hydrogenase Research
}

Henrik Land ${ }^{1}$, Moritz Senger ${ }^{2,3}$, Gustav Berggren ${ }^{1}$, and Sven T. Stripp ${ }^{3}$

\author{
${ }^{1}$ Molecular Biomimetics, Department of Chemistry, Ångström Laboratory, Uppsala \\ University, 75120 Uppsala, Sweden \\ ${ }^{2}$ Physical Chemistry, Department of Chemistry, Ångström Laboratory, Uppsala University, \\ Uppsala 75120, Sweden \\ ${ }^{2}$ Bioinorganic Spectroscopy, Department of Physics, Freie Universität Berlin, Arnimallee 14, \\ 14195 Berlin, Germany
}

\begin{abstract}
Hydrogenases are redox enzymes catalyzing the conversion of protons $\left(\mathrm{H}^{+}\right)$and molecular hydrogen $\left(\mathrm{H}_{2}\right)$. Based on the composition of the active site cofactor, the monometallic [Fe]-

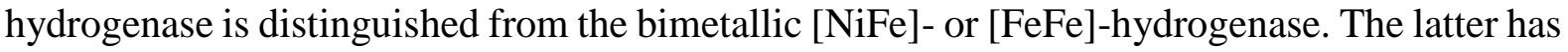
been reported with particularly high turnover activities for both $\mathrm{H}_{2}$ release and $\mathrm{H}_{2}$ oxidation, notably at neutral $\mathrm{pH}$, ambient temperatures, and negligible electric overpotential. Due to these properties, [FeFe]-hydrogenase represents the "gold standard" in enzymatic hydrogen turnover. Understanding hydrogenase chemistry is crucial for the design of transition metal complexes that may serve as sustainable proton reduction or $\mathrm{H}_{2}$ oxidation catalysts, e.g. in electrolytic devices or fuel cells.

Even 20 years after the first crystal structures of [FeFe]-hydrogenase have been published, several aspects of biological hydrogen turnover are heatedly discussed. In this perspective, we give an overview on how the diversity of naturally occurring and artificially prepared, semisynthetic [FeFe]-hydrogenases deepens our understanding of hydrogenase chemistry. In parallel, we cover new results from biophysical techniques that go beyond the scope of conventional electrochemistry, X-ray diffraction, EPR, and FTIR spectroscopy. Taking into account both proton transfer and electron transfer as well as the notorious sensitivity of [FeFe]hydrogenases towards carbon monoxide, the discussion further touches upon the molecular proceedings of biological hydrogen turnover.
\end{abstract}




\section{Contents}

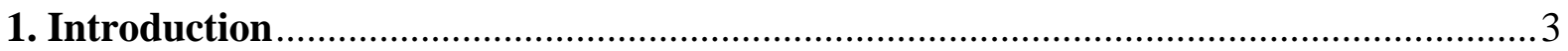

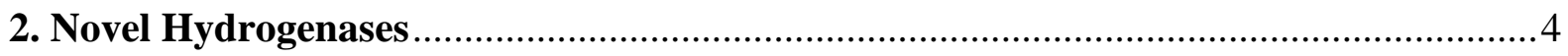

2.1 On the Diversity of [FeFe]-hydrogenase .......................................................

2.2 The Influence of F-clusters and Protein Environment ........................................ 6

2.3 Isolation of Functional [FeFe]-hydrogenase ...................................................

2.4 Artificial Maturation and Organometallic Variants.......................................... 11

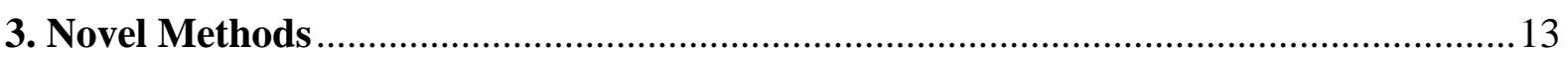

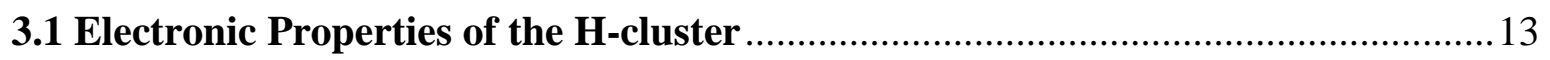

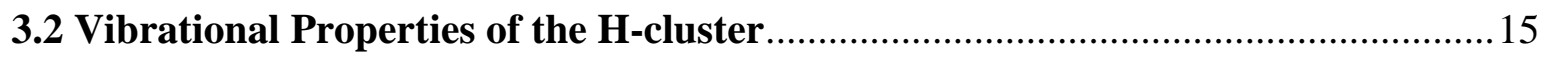

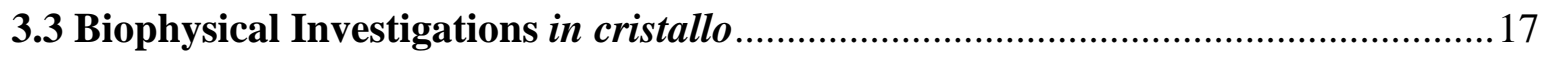

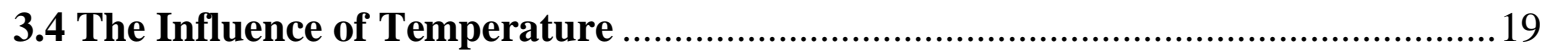

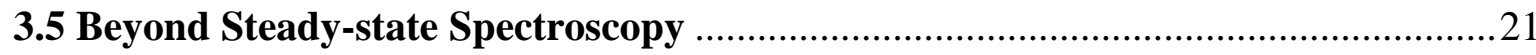

3.6 Biophysical Investigations and Electrochemistry in vivo .....................................2

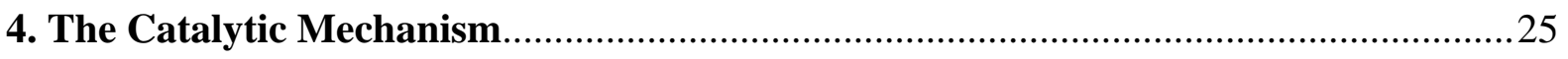

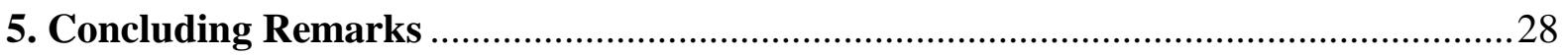

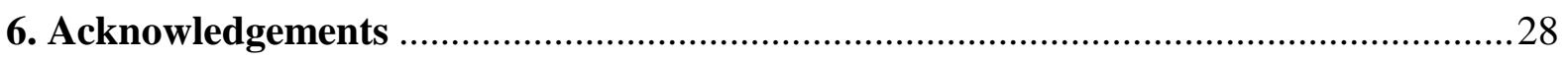

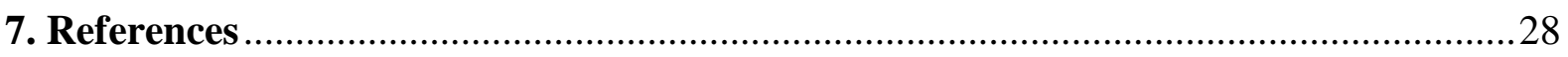




\section{Introduction}

Molecular hydrogen $\left(\mathrm{H}_{2}\right)$ is widely recognized as a green energy carrier with the potential to replace fossil fuels. ${ }^{1-3}$ Considering our interest in a 'hydrogen society', it is important to realize that evolution has already developed an efficient economy based on $\mathrm{H}_{2} \cdot{ }^{4}$ Iron-sulfur enzymes called hydrogenases are central to the hydrogen metabolism of numerous microorganisms as they catalyze the reversible conversion between protons $\left(\mathrm{H}^{+}\right)$and $\mathrm{H}_{2} .{ }^{5}$ Depending on the nature of the metal cofactor, hydrogenases are divided into three main classes denoted as [Fe]-, [NiFe]-, or [FeFe]-hydrogenases. The latter are particular efficient catalysts with $\mathrm{H}_{2}$ evolution activities surpassing $10.000 \mathrm{H}_{2} / \mathrm{s}^{6}{ }^{6}$ Phylogenetically, there are indications that [FeFe]hydrogenases could be the most recent class as archaea rely on [Fe]- and [NiFe]-hydrogenase whereas certain unicellular plants encode for [FeFe]-hydrogenase exclusively. ${ }^{7-11}$ All [FeFe]hydrogenases share a biologically unique cofactor, the hydrogen-activating 'H-cluster'. This organometallic moiety consists of a $[4 \mathrm{Fe}-4 \mathrm{~S}]$ cluster connected to a diiron site via a bridging cysteine (Figure 1). The low valence iron ions of the diiron site are bridged by an azadithiolate ligand (adt) and coordinated by the $\pi$-accepting, strong-field ligands cyanide $\left(\mathrm{CN}^{-}\right)$and carbon monoxide (CO). ${ }^{12,13}$ Details of the electronic structure and potential catalytic intermediates are discussed in Chapter 3. The biosynthesis of the H-cluster is a complex process that depends on a minimum of three specific, auxiliary enzymes. ${ }^{7}$ Through the activity of two radical SAM enzymes (HydE and HydG), a pre-catalyst is assembled on a scaffold protein (HydF) and transferred to the hydrogenase apo-protein, generating the complete H-cluster. ${ }^{14-17}$

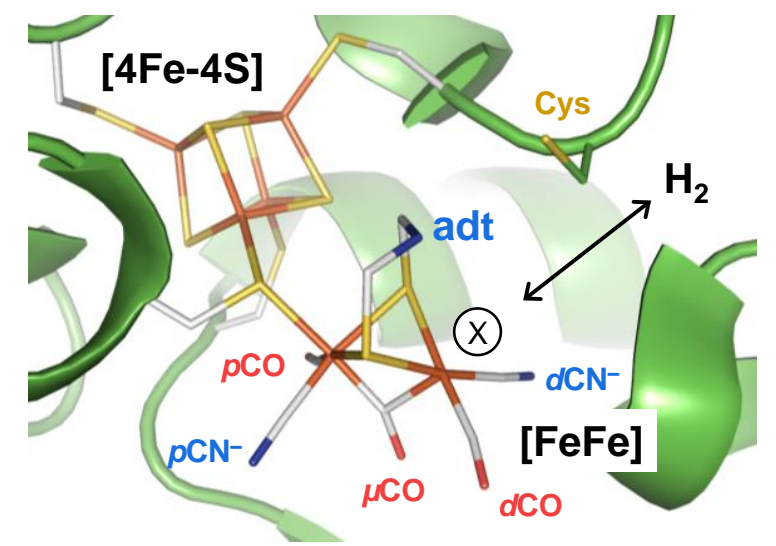

Figure 1 - The active site cofactor of [FeFe]-hydrogenase. The H-cluster comprises of a [4Fe-4S] cluster and a diiron site ([FeFe]), coordinated by two $\mathrm{CN}^{-}$ligands and three $\mathrm{CO}$ ligands. At the open coordination site of the distal iron ion $(\mathrm{X})$, gases like $\mathrm{H}_{2}, \mathrm{CO}$, and $\mathrm{O}_{2}$ react with the $\mathrm{H}$-cluster. The azadithiolate (adt) ligand mediates proton transfer between diiron site and protein fold, via a conserved cysteine residue (Cys) in prototypical [FeFe]hydrogenases. Drawn after pdb coordinates 4XDC. Legend: $\mathrm{p}$ - proximal; $\mathrm{d}$ - distal; $\mu$ - bridging 
Stephenson \& Stickland were the first to report enzymatic hydrogen activation in $1931^{18}$ and the efforts aimed at unravelling Nature's design principles for biological hydrogen conversion have accelerated quite significantly over the past 20 years. In this perspective, we cover the state-of-the-art with regards to [FeFe]-hydrogenase with an emphasis on recent insights gained by studying 'new' hydrogenases, derived from both biodiversity and artificial enzymes featuring synthetically modified cofactors (Chapter 2). Furthermore, we review trends in the spectroscopic analysis of [FeFe]-hydrogenase including transient approaches and whole-cell spectroscopy (Chapter 3). Our perspective will close on a brief note on the catalytic mechanism of [FeFe]-hydrogenase (Chapter 4).

\section{Novel Hydrogenases}

$[\mathrm{FeFe}]$-hydrogenases are widely used as inspiration for the design of molecular catalysts and it is crucial to understand their catalytic design principles. However, only a fraction of the known [FeFe]-hydrogenases are characterized to date and our knowledge on how the reactivity of the $\mathrm{H}$-cluster is influenced by the protein fold in general and the active site pocket in particular is fragmentary at best. Truncation and mutation studies have been a powerful tool in this context but typically result in a loss of function. ${ }^{19}$ In order to achieve a deeper understanding of biological hydrogen turnover, the biodiversity of [FeFe]-hydrogenases needs to be explored.

\subsubsection{On the Diversity of [FeFe]-hydrogenase}

Several studies of [FeFe]-hydrogenase biodiversity have been published. ${ }^{20-22}$ Unfortunately, none of these studies cover the full range of diversity and naming conventions are inconsistent. Herein, we provide a comprehensive summary of all [FeFe]-hydrogenase sub-classes identified to-date, organized based on their domain structure and following the naming convention put forward by Jacques Meyer, Calusinska et al., and Peters et al. (Figure 2). ${ }^{7-9}$ 
group

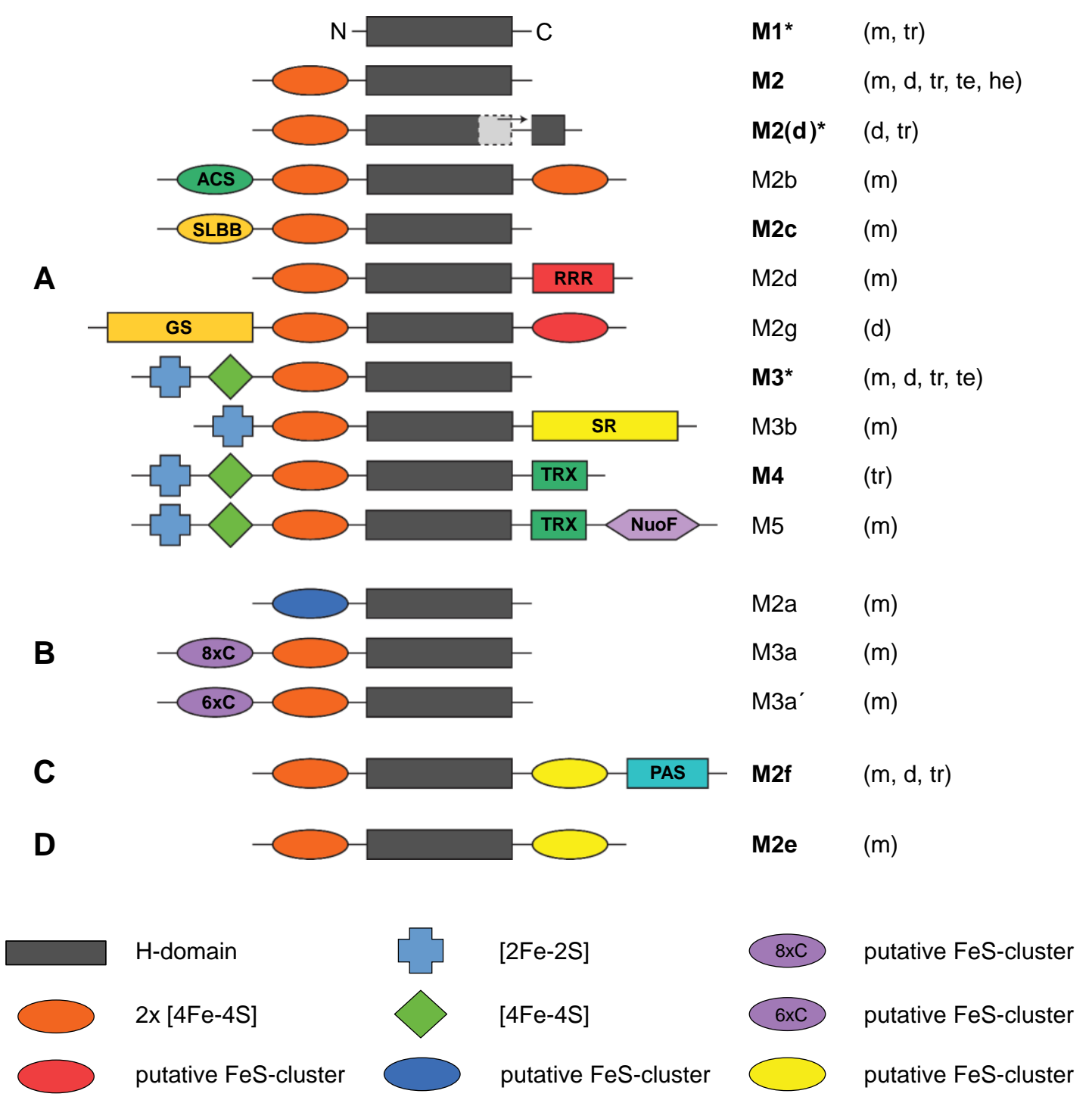

Figure 2 - Biodiversity of [ $\mathrm{FeFe}]-$ hydrogenase. Domain architecture of the catalytic subunit of all known [FeFe]hydrogenase groups A-D. Sub-classes are named after their catalytic subunit where ' $M$ ' stands for monomeric and the number is indicative of size. The lower-case letter reflects that many sub-classes have been added over the years. Sub-classes in bold indicate some degree of characterization whereas sub-classes with a crystal structure are marked $(*)$. Abbreviations in parenthesis show in which quarternary structural variations the sub-class occurs (i.e., monomeric (m), dimeric (d), trimeric (tr), tetrameric (te) and hexameric (he)). Domain abbreviations: acetylCoA synthase binding domain (ACS), soluble-ligand-binding $\beta$-grasp binding domain (SLBB), rubredoxinrubrerythrin-rubredoxin binding domain (RRR), glutamate synthase (GS), sulfite reductase (SR), thioredoxin (TRX), NADH:ubiquinone oxidoreductase chain F (NuoF), Per-Arnt-Sim domain (PAS). 
[FeFe]-hydrogenases can be separated into four distinct phylogenetic groups $\mathbf{A}-\mathbf{D}$ (Figure 2). Group A consists of prototypical and bifurcating [FeFe]-hydrogenases. In nature, prototypical [FeFe]-hydrogenases perform hydrogen turnover using ferredoxin as redox partner while bifurcating $[\mathrm{FeFe}]$-hydrogenases perform the same reaction using both ferredoxin and $\mathrm{NAD}(\mathrm{H})$ as electron donor/acceptor. ${ }^{23-25}$ This group comprises the best characterized enzymes. Moreover, the catalytically most active enzymes have been found in Group A such as the [FeFe]-hydrogenases from Chlamydomonas reinhardtii (CrHydA1, sub-class M1), ${ }^{26}$ Desulfovibrio desulfuricans ( $D d \mathrm{Hyd} \mathrm{AB}$, often referred to as $D d \mathrm{H}$, sub-class $\mathrm{M} 2(\mathrm{~d})$ ), ${ }^{27}$ and Clostridium pasteurianum and acetobutylicum ( $C p \mathrm{HydA} 1$ and $C a \mathrm{HydA} 1$, referred to as $C p \mathrm{I}$ and $\mathrm{CaI}$, sub-class M3). ${ }^{28}$ Group B is phylogenetically distinct although its three sub-classes show similar amino acid motifs around the H-cluster as Group A [FeFe]-hydrogenases. As no representative example of Group B has been characterized so far any distinct differences between Group A and Group B [FeFe]-hydrogenase remain to be discovered. Group C has been classified as 'sensory' based on the presence of a PAS domain (Figure 2). ${ }^{8,22}$ Moreover, genes encoding Group C enzymes are commonly found upstream from known $\mathrm{H}_{2}$-producing [FeFe]-hydrogenases. The biochemical characterization of the M2f-type [FeFe]-hydrogenase from Thermotoga maritima further supports the notion of a sensory function as it shows modest catalytic rates and an apparent high sensitivity towards $\mathrm{H}_{2}{ }^{29}$ The closely related subclass M2e (Group D) have a similar gene localization and domain structure to M2f-type enzymes, suggestive of a similar physiological function (Figure 2). However, the lack of a PAS domain in combination with several differences in the active-site amino acids makes their biological function unclear at the moment. ${ }^{8}$ One enzyme from this sub-class, derived from Thermoanaerobacter mathranii, has recently been partly characterized but further investigation is needed. ${ }^{30}$

\subsubsection{The Influence of F-clusters and Protein Environment}

[FeFe]-hydrogenase carries up to five additional iron-sulfur clusters including the M4 sub-class that carries an additional C-terminal cluster in the TRX domain (Figure 2). ${ }^{22}$ These ferredoxintype or 'F-clusters' act as a molecular wire through the protein ensuring efficient electron transfer between biological redox partners and the H-cluster (Figure 3). The part of the enzyme that binds the F-clusters is commonly referred to as the ' $\mathrm{F}$-domain' in variance to the ' $\mathrm{H}$ domain' that exclusively comprises the H-cluster. The F-clusters have a significant influence on the overall reactivity of the hydrogenase. This has been elucidated in the case of the two closely related M3-type enzymes from $C p \mathrm{I}$ and $C a \mathrm{I}$ as well as the sub-class M2 enzymes from 
Megasphaera elsdenii (MeHydA) and $D d \mathrm{H}^{31-34}$ In the latter case, redox titrations combined with FTIR and EPR spectroscopy revealed that the redox equilibrium of the diiron site and its $p \mathrm{~K}_{\mathrm{a}}$ is influenced by the oxidation state of the F-clusters. ${ }^{33}$ Parallel studies of $\mathrm{CaI}$ and $\mathrm{MeHydA}$ have shown that the F-clusters affects the catalytic bias of the enzyme. In both cases, removal of the F-domain resulted in enzymes favoring $\mathrm{H}_{2}$ release following a significant drop in $\mathrm{H}_{2}$ oxidation rates. $^{31,32}$
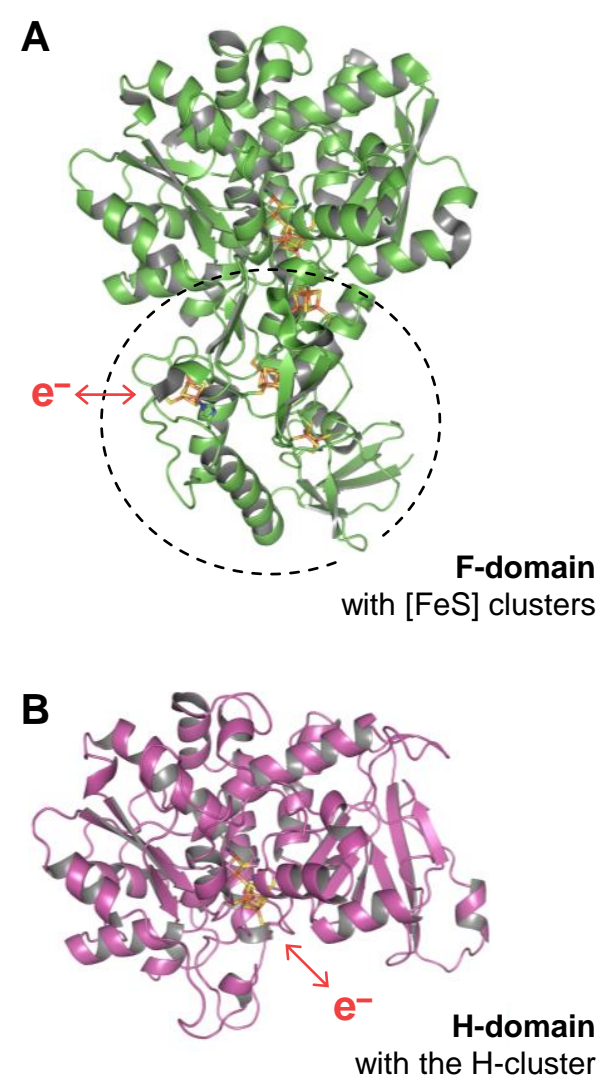

Figure 3 - Electron transfer and domain architecture of [FeFe]-hydrogenase. (A) Crystal structure of $C p I$ (M3) drawn after pdb coordinates 4XDC. The F-domain (dashed circle) carries three [4Fe-4S] clusters and a single $[2 \mathrm{Fe}-2 \mathrm{~S}]$ clusters that facilitate electron transfer between $\mathrm{H}$-cluster and the protein surface. (B) Homology model of $\mathrm{CrHydA} 1$ (M1). Here, the F-domain is missing and electrons are injected directly into the H-cluster, i.e. via the $[4 \mathrm{Fe}-4 \mathrm{~S}]$ cluster.

In addition to the F-clusters the activity of [FeFe]-hydrogenase is influenced by the mass transfer of gases (e.g., $\mathrm{H}_{2}, \mathrm{O}_{2}$, or $\mathrm{CO}$ ) and protons $\left(\mathrm{H}^{+}\right)$. Molecular dynamics simulations proposed a number of putative gas channels ${ }^{35}$, and site-directed mutagenesis could slow down $\mathrm{O}_{2}$ inactivation in individual studies. ${ }^{36}$ However, experimental proof verifying a main trajectory for gas transfer has yet to be obtained. ${ }^{37}$ There are indications that $\mathrm{H}_{2}$ diffuses more freely 
through the protein than bulky gases, and there might indeed be no such thing as a specific $\mathrm{H}_{2}$ channel. The proton transfer pathway in Group A [FeFe]-hydrogenase comprise a series of well-conserved amino acid and water residues that enable proton transfer between the H-cluster and the enzyme surface (Figure 4) ${ }^{38-40}$ It starts at the H-cluster with a cysteine residue $\left(\mathrm{C}_{1}\right)$ responsible for proton transfer to the $H$-cluster and continues with a serine $\left(S_{1}\right)$, glutamate $\left(E_{1}\right.$, $\mathrm{E}_{2}$ ), and an arginine residue $(\mathrm{R}) .{ }^{41,42}$ A methionine 'above' the H-cluster $\left(\mathrm{M}_{2}\right)$ was discussed as hydrogen-bonding partner to the adt ligand possibly providing an alternative proton transfer trajectory. ${ }^{43}$ However, in Group $\mathbf{C}[\mathrm{FeFe}]$-hydrogenases neither cysteine $\mathrm{C}_{1}$ nor methionine $\mathrm{M}_{2}$ are conserved. ${ }^{29}$ Another putative proton transfer pathway was suggested to involve a conserved lysine residue $(\mathrm{K})$ close to the distal iron ion. ${ }^{13}$ Together, this implies that more investigations on possible proton transfer pathways in [FeFe]-hydrogenase are needed, in particular to understand the chemistry of the Group C and Group D enzymes.
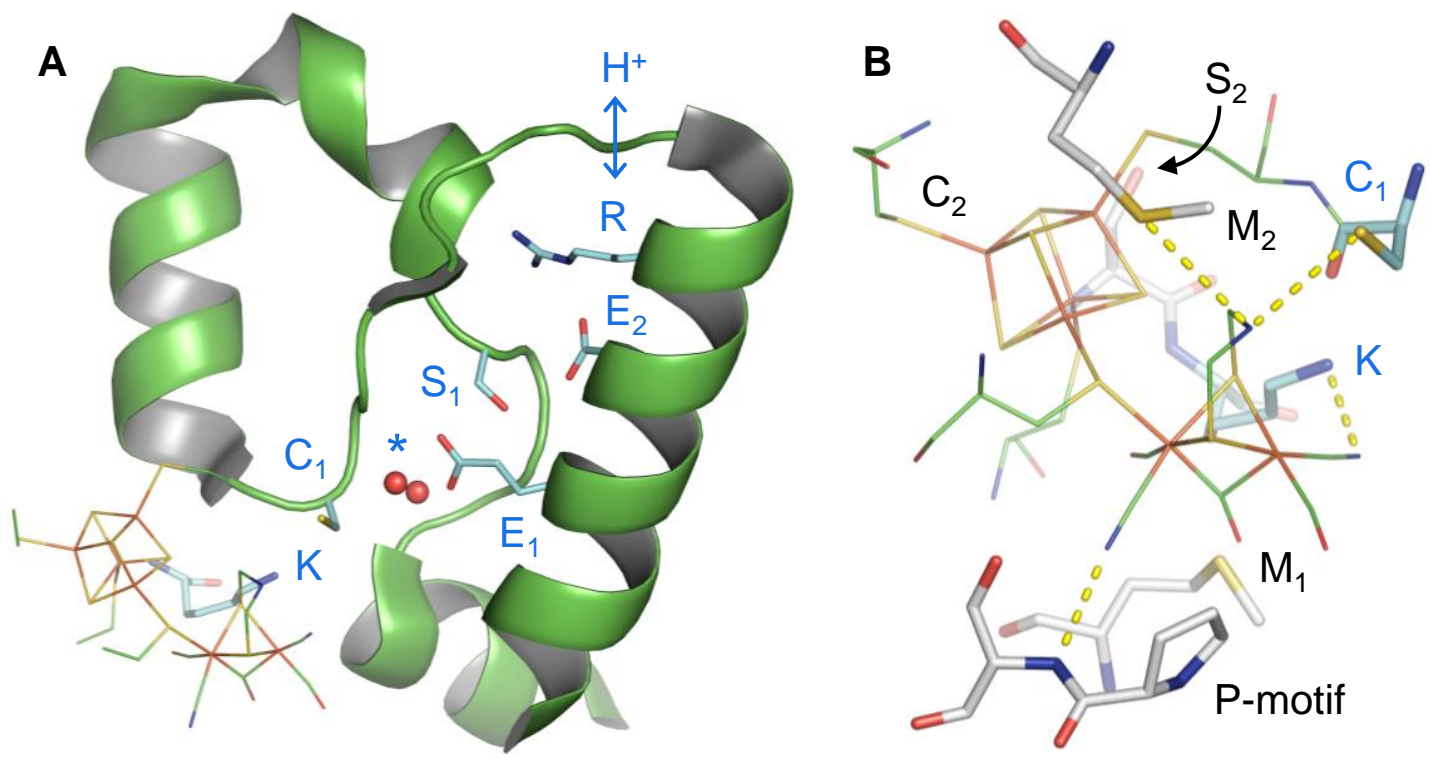

Figure 4 - Proton transfer pathway and active site niche of [FeFe]-hydrogenase. Crystal structure of $C p I$ (M3), drawn after pdb coordinates 4XDC. (A) A conserved set of amino acid residues (blue sticks and labels) and water molecules $(*)$ facilitates bidirectional proton transfer. Alternatively, lysine residue $\mathrm{K}$ was discussed to be involved in proton transfer. (B) At the diiron site, two methionine residues $\left(\mathrm{M}_{1}, \mathrm{M}_{2}\right)$ and a backbone contact including a proline residue ('P-motif') influence the H-cluster geometry and catalytic bias. The identity and protonation state of amino acid residues at the $\left[4 \mathrm{Fe}-4 \mathrm{~S}\right.$ ] cluster (including cysteine $\mathrm{C}_{2}$ and serine $\mathrm{S}_{2}$ ) has been shown to affect the electrochemical properties of the H-cluster. 
The amino acid environment of the H-cluster is suspected to play a role beyond modulating gas access and proton transfer. For example, the $\mathrm{CN}^{-}$ligands of the $\mathrm{H}$-cluster were modelled according to potential hydrogen-bonding partners, i.e. lysine $\mathrm{K}$ and a backbone contact involving a proline residue close to the proximal iron ion (Figure 4). ${ }^{19}$ While the former remains speculative, site-directed mutagenesis of the 'P-motif' had significant impact on catalytic bias and spectroscopic properties. ${ }^{44}$ This demonstrates how the protein modulates the electron density of the diiron site through Lewis acid/base interactions with the $\mathrm{CN}^{-}$ligands. At the [4Fe-4S] cluster, amino acid exchanges ${ }^{45}$ and protonation differences ${ }^{46}$ have been shown to affect the electrochemical properties of the H-cluster, and a similar effect was discussed for the orientation of a conserved serine $\left(\mathrm{S}_{2}\right.$ in Figure 4$) .{ }^{47}$ Finally, a methionine residue below the Hcluster was suggested to promote the release of $\mu \mathrm{CO}$ into a semi-bridging or terminal position upon reduction of the diiron site $\left(\mathrm{M}_{1}\right.$ in Figure 4$) .{ }^{29}$ The conservation of this methionine is a key difference between groups $\mathbf{A} / \mathbf{B}$ and $\mathbf{C} / \mathbf{D}$ and has important implications for the catalytic mechanism (Chapter 4).

\subsubsection{Isolation of Functional [FeFe]-hydrogenase}

Historically, the isolation of [FeFe]-hydrogenase has been limited by several factors. In the 1950s, enzyme isolation was dependent on homologous expression, causing significant challenges depending on the source organism. ${ }^{48}$ During the 1970 s and 1980s, heterologous overexpression in easy-to-handle host organisms such as Escherichia coli or Pichia pastoris was developed and became the method of choice for most researchers. ${ }^{49,50}$ The first example of an active [FeFe]-hydrogenase obtained in such a way was published by Posewitz et al. in 2004, following the successful co-expression of CrHydA1 with the auxiliary maturases HydEFG. ${ }^{14}$ The method was then refined by using E. coli strain BL21(DE3) $\Delta$ iscR in which deletion of the gene encoding for the transcriptional negative regulator IscR stimulates FeScluster biosynthesis. This resulted in at least a ten-fold increase in yield of active [FeFe]hydrogenase compared to previous reports. ${ }^{51,52}$ Expressing [FeFe]-hydrogenase in Clostridium acetobutylicum or Shewanella oneidensis (i.e., bacteria natively expressing the HydEFG proteins) suffered from complications in handling these organisms. ${ }^{53-55}$ In 2013, it was shown that [FeFe]-hydrogenase apo-protein can be heterologously overexpressed in inactive form and artificially activated using a synthetic mimic of the cofactor (Chapter 2.2). ${ }^{56,57}$ This breakthrough in $[\mathrm{FeFe}]$-hydrogenase isolation has paved the way for a new era in hydrogenase discovery. By taking advantage of the increasing amount of sequenced genomes ${ }^{58}$, bioinformatics can identify any [FeFe]-hydrogenase encoding gene of interest, regardless of 
the source organism. The genes can then be codon-optimized for expression in common hosts and synthesized in a matter of days. This approach was recently explored when eight putative [FeFe]-hydrogenase encoding genes from a range of different sub-classes were synthesized and expressed in E. coli. ${ }^{30}$ Notably, this was done without co-expression of HydEFG.

Outlook. Several aspects motivate discovering novel [FeFe]-hydrogenases. Firstly, mechanistic studies of [FeFe]-hydrogenase are necessary in order to understand their complex chemistry and to aid the development of efficient biomimetic catalysts. As previously mentioned, the vast majority of the characterized [FeFe]-hydrogenases originate from Group A. Although the active site architecture in this group is conserved, these enzymes still exhibit clear differences in catalytic behavior: reported rates for $\mathrm{H}_{2}$ release and $\mathrm{H}_{2}$ oxidation differ by a factor of 500 and 15.000, respectively, underscoring the influence of the non-catalytic domains on the activity of the enzyme. However, also between the closely related [FeFe]hydrogenases within the same sub-class of Group $\mathbf{A ~} \mathrm{H}_{2}$ release rates differ up to 40 times, ${ }^{4,59-}$ ${ }^{61}$ suggesting that even a detailed discrimination based on differences in domain structure and active site architecture does not allow for an impeccable prediction of catalytic activity. Clearly, aspects of the molecular determinants of [FeFe]-hydrogenase turnover kinetics are poorly understood.

Secondly, the understanding of biological hydrogen metabolism is still rather limited and from an environmental and biotechnological perspective the organisms capable of metabolizing $\mathrm{H}_{2}$ needs to be better understood. This is also relevant from a medical perspective since many of these organisms are involved in human pathogenesis. ${ }^{11}$ Beyond hydrogen turnover activity, the bifurcating, multimeric [FeFe]-hydrogenases of Group A are interesting for the study of catalytic reactions coupled to $\mathrm{H}_{2}$ turnover, e.g. $\mathrm{NAD}(\mathrm{P}) \mathrm{H}$ and $\mathrm{CO}_{2}$ conversion. ${ }^{25}$ Moreover, the [FeFe]-hydrogenase from Clostridium beijerinckii ( $\mathrm{CbA} 5 \mathrm{H}$, sub-class $\mathrm{M} 2 \mathrm{c})$ appears to display a unique tolerance towards $\mathrm{O}_{2}{ }^{62}$ These observations underscore the potential of exploring hitherto uncharacterized sub-classes in efforts to discover enzymes with unprecedented activities and properties.

Thirdly, there is a great need to increase the toolbox of available [FeFe]-hydrogenases so that the best possible candidates can be identified with regards to catalytic performance and $\mathrm{O}_{2}$ tolerance. These enzymes can then be optimized, e.g. through directed evolution and applied in industrial $\mathrm{H}_{2}$ production or in biotechnological devices such as fuel cells. ${ }^{63}$ In the next chapter, we will discuss modification of the active site cofactor beyond the scope of nature. 


\subsection{Artificial Maturation and Organometallic Variants}

The biosynthesis of the $\mathrm{H}$-cluster proceeds via a readily isolatable intermediate containing the [4Fe-4S] cluster but lacking the diiron site. ${ }^{64,65}$ This assembly line could be hijacked through the introduction of synthetic analogues of the diiron site ('artificial maturation') enabling the preparation of semi-synthetic [FeFe]-hydrogenases (Figure 5).${ }^{56,57}$ More recently, this strategy has been utilized to identify possible intermediates in the assembly of the pre-catalyst. ${ }^{66-68}$ Arguably, the main impact of artificial maturation to-date has been the simplified preparation of the active enzyme ${ }^{60,69}$ including site-selective isotopologues, ${ }^{70-72}$ which also facilitates rapid screening protocols. ${ }^{30}$ Another important aspect is the preparation of [FeFe]-hydrogenases in which the diiron site is synthetically modified in order to generate non-natural H-clusters and enzymes with new properties. ${ }^{73-76}$

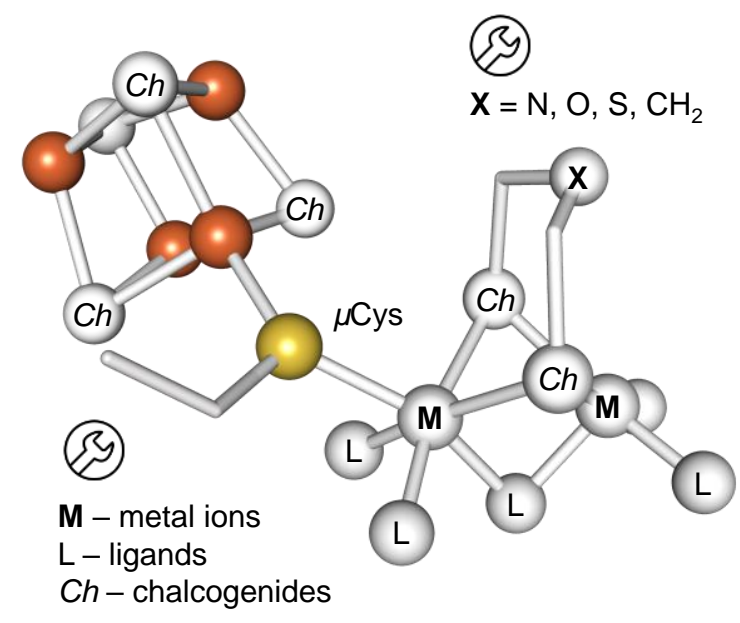

Figure 5 - The H-cluster as a toolbox. Several organometallic variants comprising non-natural cofactors have been reported. Modifications include different metal ions (M) and metal ligands (L), the replacement of sulfur against selenium $(\mathrm{Ch})$, and different variations of the dithiolate headgroup $(\mathrm{X})$.

In the case of Group A [FeFe]-hydrogenase, the active site cavity has been extensively explored through site-directed mutagenesis (Chapter 2.1.2). ${ }^{19,43-46}$ Of particular note in the context of organometallic variants is the critical importance of hydrogen-bonding interactions between $\mathrm{C}_{1}$ (Figure 4 ) and the central nitrogen atom of the adt group. ${ }^{39}$ Artificial maturation has enabled detailed studies of this proton transfer pathway and facilitated the discovery of a number of proton-coupled electron transfer events relevant to the catalytic cycle of the $\mathrm{H}$ cluster, i.e. through manipulations of the diiron site rather than the protein (Figure 5). For example, diiron complexes that carry propanethiolate (pdt) or oxodithiolate (odt) ligands 
instead of the natural adt ligand can be incorporated into the apo-protein with good yields. Such variants showed very specific turnover characteristics and allowed locking the H-cluster in specific oxidation states (Chapter 3.1). ${ }^{56,57}$ Numerous other organometallic variants have been reported, documenting modifications all across the H-cluster (Figure 5). The iron ions have been replaced by ruthenium, resulting in the formation of $\mathrm{a}[\mathrm{RuRu}]$ bridging hydride species that appears highly stable. ${ }^{77}$ The chalcogens have been changed from sulfur to selenium in both the $[4 \mathrm{Fe}-4 \mathrm{~S}]$ cluster as well as the diiron site. ${ }^{78,79}$ The latter variant showed a shift in catalytic bias towards $\mathrm{H}_{2}$ release, but also suffered from a significant decrease in cofactor stability. Modifications of the diatomic ligands revealed that monocyanide variants of the H-cluster retain remarkable residual activity both in vitro and in whole cells. ${ }^{79-83}$

Outlook: The preparation of organometallic mutants will undoubtedly continue contributing to our mechanistic understanding of [FeFe]-hydrogenase. The preparation of modified $\mathrm{H}-$ clusters outcompeting the native cofactor remains a significant challenge, although the Selenium analogue appears to improve $\mathrm{H}_{2}$ release activity. ${ }^{78,79}$ It is noteworthy that synthetic modification of the diiron site have a dramatic effect on the reactivity towards known inhibitors. ${ }^{83}$ Thus, it arguably provides a convenient route towards more stable catalysts. In parallel to the enzymology aspect, the generation of highly active, semi-synthetic [FeFe]hydrogenases is of particular relevance in the context of designing small molecule systems. Since the structural elucidation of the H-cluster two decades ago, ${ }^{12,13}$ the design and characterization of synthetic $[\mathrm{FeFe}]$ complexes has been a highly active research field, and several comprehensive reviews have been published on the topic. ${ }^{84-86}$ Historically, this work has been critical, e.g. in assigning the nature of the diatomic ligands, identifying the nature of the bridgehead atom, highlighting the importance of acid/base residues in the vicinity of the metal sites, and mapping out the reactivity of terminal $v s$. bridging hydrides. In solution, such small molecule mimics generally display limited catalytic efficiencies; however, upon incorporation into the enzyme unstable complexes are transformed into highly active catalysts. This immediately underscores the importance of the $[4 \mathrm{Fe}-4 \mathrm{~S}]$ cluster and the protein environment for activity (Chapter 2.1.2). Analogously, the catalytic properties of small molecule systems can be significantly improved through the addition of redox and acid/base functionalities, or by incorporating them into polymers. ${ }^{87-90}$ In order to disentangle the different effects of the protein fold on the reactivity of artificial [FeFe] complexes, it is highly relevant to complement studies of different sub-classes of [FeFe]-hydrogenase with model systems featuring redox active ligands in combination with a more elaborate $2^{\text {nd }}$ coordination sphere. 


\section{Novel Methods}

The electronic structure of the H-cluster has been investigated by continuous-wave and pulsed EPR spectroscopic techniques as well as Mössbauer spectroscopy and nuclear inelastic scattering (NIS). Similarly, the $\mathrm{CO}$ and $\mathrm{CN}^{-}$ligands of the $\mathrm{H}$-cluster provide exquisite spectroscopic handles for vibrational spectroscopy and FTIR spectroscopy has arguably become the method of choice in the field. Albeit not novel methods, they are continuously employed in the identification of new states of potential catalytic relevance. In the following section, we will outline how these methods have provided a foundation for our current mechanistic understanding, before describing how they are used in new ways to provide even more detailed insight into H-cluster chemistry. In addition, recent data from synchrotron methods is discussed.

\subsubsection{Electronic Properties of the H-cluster}

The paramagnetic resting state Hox that gives rise to a rhombic signal ( $g=2.10,2.04,2.00$; see Figure 6$)^{*}$ representing the oxidized $[4 \mathrm{Fe}-4 \mathrm{~S}]$ cluster $(+2)$ and a mixed-valence diiron site $\left(\mathrm{Fe}_{\mathrm{p}}(\mathrm{II})-\mathrm{Fe}_{\mathrm{d}}(\mathrm{I}),+3\right) .{ }^{91-93}$ The symmetry of the formally diamagnetic [4Fe-4S] cluster (i.e., a pair of $\mathrm{Fe}(\mathrm{II}) \mathrm{Fe}(\mathrm{III})$ with $\mathrm{S}=9 / 2)$ is broken due to spin exchange with the diiron site $(\mathrm{S}=1 / 2)$. Lubitz et al. noted that the strong electronic contact facilitates electron transport between $[4 \mathrm{Fe}-$ $4 \mathrm{~S}$ ] cluster and diiron site. ${ }^{94}$ Accordingly, the putative protonation of the $[4 \mathrm{Fe}-4 \mathrm{~S}]$ cluster in HoxH (see below) is observable by EPR (Figure 6). Upon CO inhibition, spin coupling is significantly enhanced in favor of the [4Fe-4S] cluster leading to an axial EPR spectrum with $\mathrm{g}=2.05$ and 2.01 in Hox-CO (Figure 6).${ }^{95,96}$ Studying the ${ }^{14} \mathrm{~N}$ hyperfine interactions, Silakov et al. revealed the chemical nature of the dithiolate group resolving a long-running controversy whether its central atom is an oxygen (odt), carbon (pdt) or nitrogen atom (adt) in favor of the latter. ${ }^{97}$ Proton-coupled electron transfer involving the amine bridgehead of the adt ligand results in the formation of the diamagnetic state $\operatorname{Hred}\left(\mathrm{Fe}_{\mathrm{p}}(\mathrm{I})-\mathrm{Fe}_{\mathrm{d}}(\mathrm{I}),+2\right)$. Here, the $[4 \mathrm{Fe}-4 \mathrm{~S}]$ cluster remains oxidized. ${ }^{92}$ Further reduction of this species gives the rhombic EPR spectrum of a [4Fe-4S] cluster (+1) characteristic for the "super-reduced" H-cluster, Hsred $(\mathrm{g}=2.08$, 1.94, 1.87). ${ }^{98,99}$ Often, these states are referred to as $\mathrm{HredH}^{+}$and $\mathrm{HsredH}^{+}$in literature. Due to spin coupling, the H-cluster is EPR-silent also when only the [4Fe-4S] cluster is reduced (Hred' and Hred'-CO). ${ }^{100}$ More recently, an H-cluster species with a terminal hydride was discovered, the so-called hydride state (Hhyd). ${ }^{101-103}$ EPR, Mössbauer, and FTIR spectroscopy

\footnotetext{
* Unless otherwise noted all EPR data in this chapter is related to $C r$ HydA1. A comprehensive summary of EPR data from also other $[\mathrm{FeFe}]$ hydrogenases can be found in ref. 5 .
} 
identified the latter as a "super-oxidized" diiron site $\left(\mathrm{Fe}_{\mathrm{p}}(\mathrm{II})-\mathrm{Fe}_{\mathrm{d}}(\mathrm{II}),+4\right)$ coupled to a reduced [4Fe-4S] cluster $(+1)$, giving rise to a rhombic EPR spectrum $(g=2.07,1.93,1.88)$ quite similar to Hsred (Figure 6). ${ }^{101}$ Further, the EPR spectrum of Hhyd bears similarities to the inactive Htrans state $(\mathrm{g}=2.06,1.96,1.89$ as observed in $D d \mathrm{H}) .{ }^{98}$ Direct proof for the presence of a terminal hydride was presented by Reijerse et al. who applied NIS on ${ }^{57} \mathrm{Fe}$-enriched samples of $C r$ HydA1-odt investigating the low-frequency Fe-H vibration at $\sim 730 \mathrm{~cm}^{-1}$ and $\sim 670 \mathrm{~cm}^{-}$ ${ }^{1} \cdot{ }^{104}$ Figure 7 depicts the electronic configuration of key H-cluster intermediates.
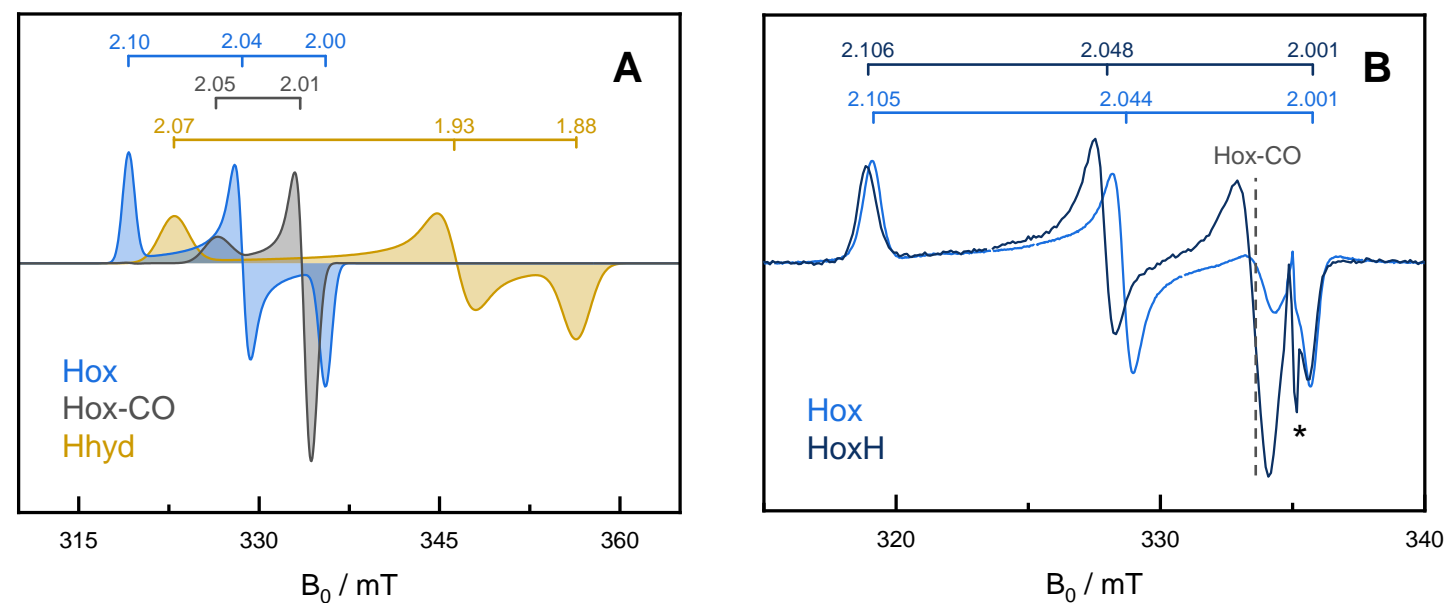

Figure 6 - EPR signatures of the H-cluster in key redox states. All data for $C r H y d A 1$. (A) Simulations of EPR spectra for the oxidized states Hox and Hox-CO as well as the reduced state Hhyd. The g-values are indicated. (B) Experimental EPR spectra of the oxidized state Hox and the oxidized protonated state HoxH reproduced a subtle shift in g-tensors. Both samples show a contamination with Hox-CO and artifacts of the quartz cuvette $(*)$. Experimental conditions: $\mathrm{T}=15 \mathrm{~K}$, frequency $=9.4 \mathrm{GHz}$, microwave power $=4 \mu \mathrm{W}$, modulation frequency/ amplitude $=100 \mathrm{kHz} / 0.5 \mathrm{mT}$, and conversion time $=60 \mathrm{~ms}$. 


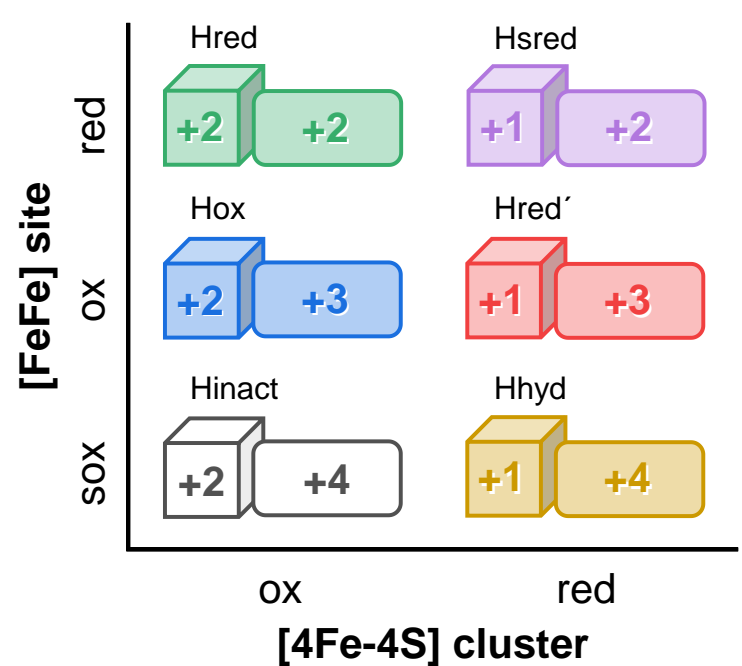

Figure 7 - Electronic properties of key redox states. The [4Fe-4S] cluster is drawn as a cube, the diiron site is represented by a rectangular box. The abbreviations refer to reduced ('red'), oxidized ('ox'), and super-oxidized ('sox'). The following details are not shown (see text): The electronic configuration of Hox-CO and Hred'-CO is the same as in Hox and Hred', respectively. Hhyd binds a terminal hydride, which contributes two additional electrons. Similarly, Hred and Hsred can be described as with an Fe(II)-Fe(II) site and a bridging hydride. An isoelectronic transition from Hsred to Hhyd might be possible. Htrans, the one-electron reduced form of Hinact, would occupy the same position as Hhyd in this diagram.

\subsubsection{Vibrational Properties of the H-cluster}

The $\mathrm{CO}$ and $\mathrm{CN}^{-}$ligands preserve the low-spin character of the diiron site and couple the $\mathrm{H}$ cluster to the protein environment. ${ }^{44,105,106}$ Making use of FTIR spectroscopy, the CO/CN ${ }^{-}$ stretching frequencies can be addressed as intrinsic marker bands (Figure 8). They are characteristic for the geometry and the protonation state of all H-cluster intermediates independent of magnetic properties and ${ }^{57} \mathrm{Fe}$ labelling. For example, the Hox state shows a clear pattern of five bands that were assigned to uncoupled stretching vibrations of the $\mathrm{CO}$ and $\mathrm{CN}^{-}$ligands at each iron ion and a Fe-Fe bridging carbonyl $(\mu \mathrm{CO})$ vibration at lower frequencies. ${ }^{107}$ Under acidic conditions, the small linear upshift of vibrational frequencies in the protonated resting state HoxH (mean off-set $\sim 6 \mathrm{~cm}^{-1}$ relative to Hox) was assigned to a protonation event at the $[4 \mathrm{Fe}-4 \mathrm{~S}]$ cluster. Uniform shifts were observed between Hred' and $\operatorname{Hred}^{\prime} \mathbf{H}^{108}$, and a recent X-ray free electron laser (XFEL) structure suggests that changes in the orientation of a serein near the $[4 \mathrm{Fe}-4 \mathrm{~S}]$ cluster $\left(\mathrm{S}_{2}\right.$ in Figure 4$)$ may have an effect similar to an adjacent protonation. ${ }^{47}$ On the opposite, the small linear downshift of frequencies in the transition from Hox to Hred' (mean off-set $\sim 5 \mathrm{~cm}^{-1}$ ) suggested reduction to the [4Fe-4S] cluster most likely concerted with a protonation event at the same site. ${ }^{108,109}$ The hydride state 
Hhyd represents an $\mathrm{H}$-cluster species with most of the electron density located at the $\mathrm{Fe}_{\mathrm{d}}-\mathrm{H}^{-}$ bond and the [4Fe-4S] cluster formally rendering the diiron site a 'super-oxidized' $\mathrm{Fe}(\mathrm{II})-\mathrm{Fe}(\mathrm{II})$ species. ${ }^{101-104}$ This results in a mean upshift of the $\mathrm{CO} / \mathrm{CN}^{-}$signature by $\sim 20 \mathrm{~cm}^{-1}$ relative to Hox, which is comparable to Htrans. ${ }^{110}$ Apparently, the terminal hydride species and the reduced $[4 \mathrm{Fe}-4 \mathrm{~S}]$ cluster damp the frequency increase expected from the oxidation of the diiron site. In comparison to $\mathbf{H o x} / \mathbf{H o x H}$ and $\mathbf{H r e d}^{\prime} / \mathbf{H r e d}^{\prime} \mathbf{H}$, the irregular shift of frequencies in HhydH $^{+}$against Hhyd may stem from protonation of the amine headgroup of the adt ligand. ${ }^{101,111}$
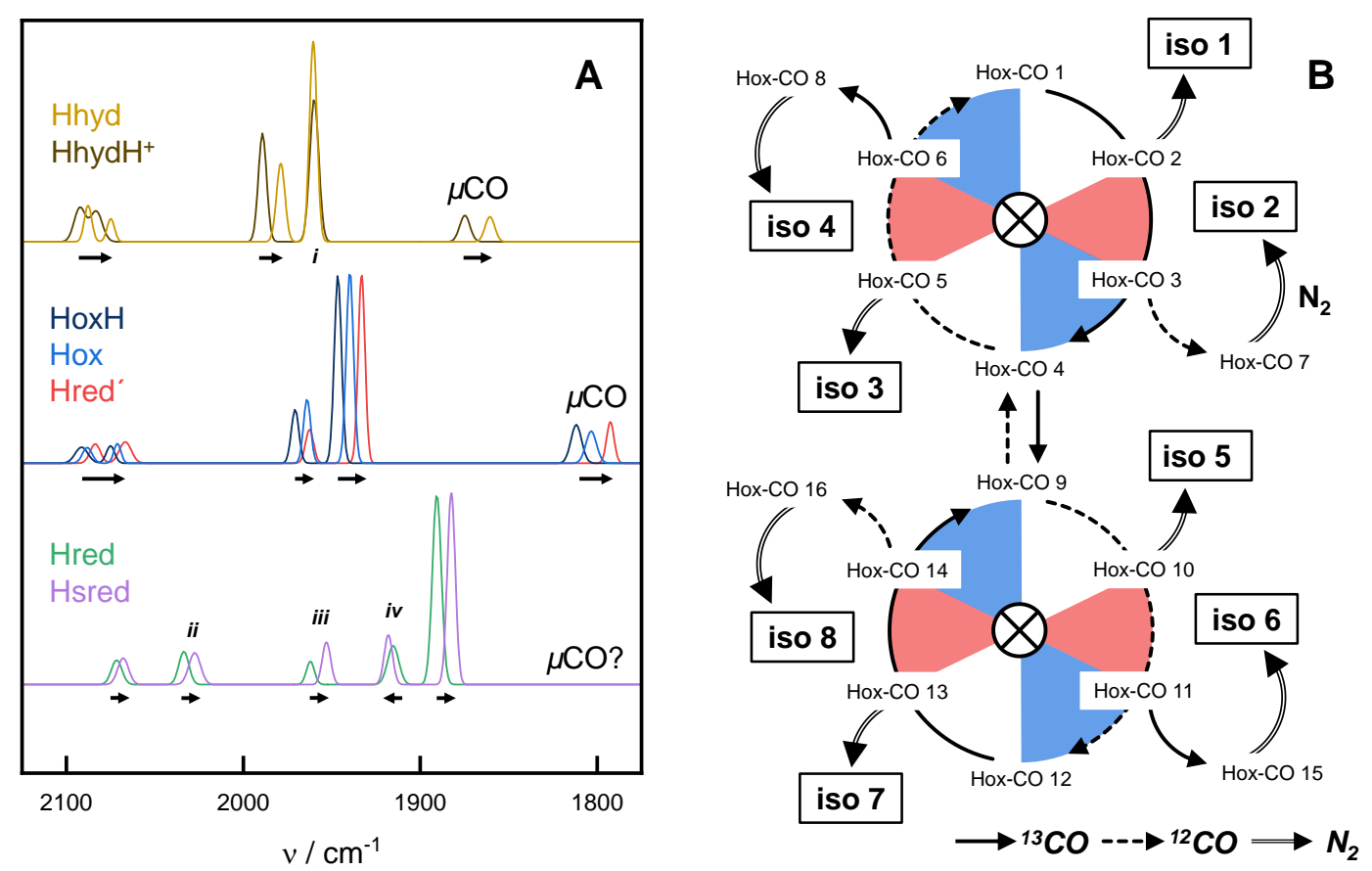

Figure 8 - IR signature of the H-cluster in key redox states and isotope editing. All data for $C r H y d A 1$. (A) Gaussian fits of experimental IR spectra for $\mathrm{Fe}(\mathrm{II})-\mathrm{Fe}(\mathrm{II}), \mathrm{Fe}(\mathrm{II})-\mathrm{Fe}(\mathrm{I})$, and $\mathrm{Fe}(\mathrm{I})-\mathrm{Fe}(\mathrm{I})$ species of the H-cluster (top to bottom). Arrows highlight spectral shifts that were assigned to protonation and/or redox differences at the [4Fe-4S] cluster. Note the following irregularities: (i) Relative to Hox/HoxH and Hred'/Hred'H the shift between Hhyd and $\mathbf{H h y d H} \mathbf{H}^{+}$is less regular. (ii) One of the $\mathrm{CN}^{-}$ligands is strongly downshifted in Hred and Hsred. (iii) The conversion of $\mu \mathrm{CO}$ into a terminal CO ligand upon reduction of the diiron site is under discussion. (iv) Note the inversion of band frequencies. (B) Site-selective ${ }^{13} \mathrm{CO}$ isotope editing of [FeFe]-hydrogenase under different illumination conditions (white area, dark; red area, $640 \mathrm{~nm}$; blue area, $460 \mathrm{~nm}$ ). The technique allows accumulation of all CO isotopomers of Hox-CO (1-16) and non-inhibited H-cluster states (isotopomers 1 - 8). See ref. 112 for details. 
The vibrations of the $\mathrm{CO} / \mathrm{CN}^{-}$ligands are largely uncoupled in the 'Hox-like' states with a $\mu \mathrm{CO}$ geometry and an open coordination site or terminal hydride ligand at $\mathrm{Fe}_{\mathrm{d}}$. Other H-cluster states exhibit pronounced vibrational coupling, e.g. upon reduction of the diiron site or CO inhibition. ${ }^{100,107,110}$ Here, site-selective ${ }^{13} \mathrm{CO}$ isotope editing (Figure 8) in combination with quantum mechanical (QM) calculations allows unraveling the structure of H-cluster intermediates with great precision, i.e. simulating the coupling patterns for a given structure with respect to the change in mass. ${ }^{113}$ The statistics obtained in such experiments ${ }^{\dagger}$ suggested the presence of an apical $\mathrm{CN}^{-}$ligand in Hox-CO and Hred'-CO hydrogen-bonded to adtNH. ${ }^{83,112,114}$ Moreover, the vibrational energy transfer in Hred and Hsred at room temperature hints at a cofactor geometry with an apical $d \mathrm{CO}$ ligand and a Fe-Fe bridging hydride $(\mu \mathrm{H}) .{ }^{115}$ Cryogenic FTIR, on the opposite, suggested a diverging band pattern for these states (Chapter 3.3) incompatible with a $\mu \mathrm{H}$ ligand. Independent of temperature, these states show a number of further irregularities, e.g. the large downshift of the $p \mathrm{CN}^{-}$frequency and upshift of the $p \mathrm{CO}$ ligand upon reduction of the $[4 \mathrm{Fe}-4 \mathrm{~S}]$ cluster. The conflicting proposals for the geometry of Hred and Hsred are discussed in the next chapter.

\subsection{Biophysical Investigations in cristallo}

Resolving the crystal structure of the $[\mathrm{FeFe}]$-hydrogenase from $C$. pasteurianum and $D$. desulfuricans by X-ray diffractometry (XRD) enabled a molecular understanding of hydrogen catalysis. ${ }^{12,13}$ Hot on the heels of the resting state Hox, $C p$ I was crystallized in the presence of $\mathrm{CO}^{116-118}$ and $D d \mathrm{H}$ was crystallized in the presence of $\mathrm{H}_{2}{ }^{119}$ resulting in H-cluster geometries that served as models for Hox-CO and Hred, respectively. Albeit crystal structures provide an exceptionally strong starting point for understanding [FeFe]-hydrogenase catalysis detailed insight into the structural dynamics of the H-cluster is dependent on spectroscopy and QM calculations. As discussed in the preceding chapter, alternative ligand orientations in Hox-CO,

Hred, and Hsred have been proposed. The limited spatial resolution of XRD on protein crystals impedes a distinction between the diatomic ligands at the $\mathrm{H}$-cluster, which is why $\mathrm{CO}$ and $\mathrm{CN}^{-}$were assigned according to potential hydrogen-bonding contacts with the protein fold in the oxidized state. ${ }^{12,13}$ At the proximal iron ion, the original $\mathrm{CO} / \mathrm{CN}^{-}$assignment was found to be correct. ${ }^{44}$ But while the crystal structure of CO-inhibited enzyme was modelled with an apical CO ligand (position ' $\mathrm{X}$ ' in Figure 1), ${ }^{116-118}$ vibrational coupling clearly suggested two equatorial carbonyls and an apical $\mathrm{CN}^{-}$ligand at the distal iron ion in Hox-CO. ${ }^{12-114}$ This

\footnotetext{
${ }^{\dagger}$ For $\mathrm{x}$ different isotopes and $\mathrm{y}$ different ligands these are $\mathrm{x}^{\mathrm{y}}$ isotopomers. ${ }^{13} \mathrm{CO}$ isotope editing of the H-cluster allows accumulating $2^{4}=16$ isotopomers of Hox-CO and $2^{3}=8$ isotopomers of non-inhibited states.
} 
implies pronounced rotational freedom of ligands. Such dynamics are likely to play a role in the reaction with molecular oxygen ${ }^{120}$ and the accumulation of the diiron-site reduced states Hred and Hsred if these indeed feature a $\mu \mathrm{H}$ ligand. The crystal structure of reduced [FeFe]hydrogenase $D d \mathrm{H}$ showed a partial release of the $\mu \mathrm{CO}$ ligand, which was suggested to be a feature of the reduced diiron site. ${ }^{119}$ At first glance, this interpretation is supported by room temperature IR spectroscopy as neither $D d \mathrm{H}$ nor $C r \mathrm{HydA} 1$ show a low frequency peak in the IR signature of Hred (compare Figure 8). ${ }^{110,121}$ But the vibrational coupling observed in Hred and Hsred is not compatible with a 'semi-bridging CO' geometry and rather suggests an apical $\mathrm{CO}$ ligand, ${ }^{115}$ which would explain the observed protection against external $\mathrm{CO}$ binding, too. ${ }^{83}$ Interestingly, cryogenic IR spectroscopy indicated a bridging ligand for both Hred and Hsred. ${ }^{122-124}$ This is in agreement with a recent study by Artz et al. comparing cryogenic $C p \mathrm{I}$ crystal structures solved with both synchrotron radiation and the free electron laser (XFEL) light source at Stanford. ${ }^{47}$ The authors were able to quantify the extent of photoreduction suggesting that in the presence of strong reductant up to $50 \%$ of $C p \mathrm{I}$ was found in a "more reduced conformation" featuring the $\mathrm{H}$-cluster in a $\mu \mathrm{CO}$ geometry. The influence of temperature is discussed in the next chapter.

Outlook. Crystallized in the presence of $\mathrm{H}_{2}$, the structure of $D d \mathrm{H}$ provides insight into the reduced form(s) of the H-cluster. ${ }^{119}$ However, a pure accumulation of Hred has never been proven in cristallo and the coordinates as reported by Nicolet et al. in 2001 most likely represent an ensemble of different reduced $\mathrm{H}$-cluster intermediates. To assign XRD structural data, it will be necessary to investigate protein crystals by spectroscopy. For example, singlecrystal EPR spectroscopy was reported for [FeFe]-hydrogenase by Sidabaras et al. only recently. ${ }^{125}$ Unfortunately, EPR spectroscopy is only of limited use investigating reduced $\mathrm{H}$ cluster states (Chapter 3.1.1). To this end, Ash et al. reported a FTIR spectro-electrochemical setup that allows probing single protein crystals by in situ IR microscopy as a function of applied potential. ${ }^{126}$ At the example of [NiFe]-hydrogenase the authors could show how the crystalized enzyme switches from a reduced state (Ni-R) to an oxidized state (Ni-B), and vice versa. In the future, similar experiments will facilitate a validation of [FeFe]-hydrogenase redox states formed in cristallo, e.g. in the process of crystal growth under $\mathrm{H}_{2}$ or $\mathrm{CO}$. More elegantly, the enzyme could be adjusted to the redox state of interest electrochemically in situ, i.e. directly ahead of the XRD experiment. Within a relatively narrow time-frame, combining IR absorbance and XRD in a single setup will be feasible. ${ }^{127}$ 


\subsection{The Influence of Temperature}

While many techniques demand refrigeration or cryogenic temperatures $<90 \mathrm{~K}$ (e.g., synchrotron XRD and XAS/XES, NIS, Raman, EPR, and Mössbauer spectroscopy) others are compatible with ambient conditions (e.g., FTIR and UV/vis spectroscopy, protein film electrochemisty, and biochemical analyses). With respect to [FeFe]-hydrogenase, recent results indicate that a direct comparison is not always possible, in particular regarding the geometry of the reduced H-cluster. Making use of FTIR spectro-electrochemistry under ambient conditions, several groups demonstrated the loss of the $\mu \mathrm{CO}$ ligand into a terminal position upon accumulation of Hred and Hsred. ${ }^{110,115,119,121}$ These findings were supported by investigations on $\mathrm{H}_{2}$ - and/or dithionite-reduced enzyme under ambient conditions, albeit to a greater variety of redox states (i.e., including Hhyd). ${ }^{83,128}$ Co-accumulation with Hred' complicated the assignment of Hred and led to the incorrect conclusion that Hred carries a $\mu \mathrm{CO}$ ligand in $\mathrm{CrHydA} 1 .{ }^{99}$ Once Hred' had been properly identified ${ }^{46,108}$, the absence of a classic $\mu \mathrm{CO}$ ligand in Hred and Hsred was largely agreed upon. The crystal structure of reduced $D d \mathrm{H}$ seemed to support this, as discussed in Chapter 3.2. ${ }^{119}$

Making use of FTIR spectroscopy on $\mathrm{H}_{2}$ and dithionite-reduced hydrogenase under cryogenic conditions, three recent studies identified low-frequency bands that were not observed at ambient temperatures. For $D d \mathrm{H}, C r \mathrm{HydA} 1$, and $C a \mathrm{I}$ these bands were assigned to a $\mu \mathrm{CO}$ ligand in Hred $\left(\sim 1810 \pm 7 \mathrm{~cm}^{-1}\right)$ and Hsred $\left(\sim 1790 \pm 12 \mathrm{~cm}^{-1}\right) \cdot{ }^{122-124}$ The experimental variance is surprisingly high, given that the $\mu \mathrm{CO}$ band is usually well conserved among Group A [FeFe]hydrogenases (Table 1). More importantly, the $\mu \mathrm{CO}$ frequencies are in the same range as Hox and Hred' (Figure 8), which hints at a Fe(II)-Fe(I) configuration rather than $\mathrm{Fe}(\mathrm{I})-\mathrm{Fe}(\mathrm{I})$. The $\mu \mathrm{CO}$ ligand is an excellent reporter of the electron density distribution across the diiron site due to his symmetric position between $\mathrm{Fe}_{\mathrm{p}}$ and $\mathrm{Fe}_{\mathrm{d}}$ (Figure 1). Additionally, the $\mu \mathrm{CO}$ vibration is uncoupled from the terminal CO ligands ${ }^{46}$, which allows interrogating the $\mu \mathrm{CO}$ vibration for protonation and redox differences independent of H-cluster geometry. The difference between $\mathrm{Fe}(\mathrm{II})-\mathrm{Fe}(\mathrm{II})$ in Hhyd and $\mathrm{Fe}(\mathrm{II})-\mathrm{Fe}(\mathrm{I})$ in $\mathbf{H o x}$ is $\sim 60 \mathrm{~cm}^{-1}$, for example (Figure 8). ${ }^{103}$ In the Group C $[\mathrm{FeFe}]$-hydrogenase from T. maritima Hred and Hsred carry a $\mu \mathrm{CO}$ ligand, presumably due to the lack of methionine $\mathrm{M}_{1}$ (Chapter 2.1.2). Here, the difference between $\mathrm{Fe}(\mathrm{II})-\mathrm{Fe}(\mathrm{I})$ in $\mathbf{H o x}$ and $\mathrm{Fe}(\mathrm{I})-\mathrm{Fe}(\mathrm{I})$ in Hsred is $\sim 50 \mathrm{~cm}^{-1} .{ }^{29}$ It should be mentioned that a similar low frequency peak has been assigned to Hox in $\mathrm{CpII} .{ }^{47}$ 
Table 1. Infrared signature of Hox for different Group A [FeFe]-hydrogenases. The $\mathrm{CO} / \mathrm{CN}^{-}$ frequencies are given in $\mathrm{cm}^{-1}$.

\begin{tabular}{lllllll}
\hline enzyme & $\boldsymbol{p C N}$ & $\boldsymbol{d C N}$ & $\boldsymbol{p C O}$ & $\boldsymbol{d C O}$ & $\boldsymbol{\mu C O}$ & ref. \\
\hline$D d \mathrm{H}$ & 2093 & 2078 & 1965 & 1940 & 1802 & 110 \\
$C r \mathrm{HydA}$ & 2088 & 2070 & 1964 & 1940 & 1802 & 99 \\
$C b \mathrm{~A} 5 \mathrm{H}$ & 2091 & 2080 & 1964 & 1940 & 1800 & 62 \\
$M e \mathrm{HydA}$ & 2087 & 2079 & 1964 & 1937 & 1803 & 60 \\
$C p \mathrm{I}$ & 2081 & 2069 & 1970 & 1947 & 1801 & 47 \\
$C a \mathrm{I}$ & 2082 & 2070 & 1970 & 1947 & 1802 & 122 \\
\hline
\end{tabular}

Based on the observation that the terminal CO ligands do not significantly change with temperature, Birrell et al. speculate that the $\mu \mathrm{CO}$ ligand in Hred and Hsred is present under ambient conditions as well, i.e. with a reduced absorption coefficient that impedes detection. ${ }^{123}$ Arguably, the observed differences of $\pm 4 \mathrm{~cm}^{-1}$ for the terminal CO ligands hint at structural changes in the H-cluster environment, i.e. involving residues directly interacting with the cofactor (Chapter 2.1.2) rather than independent H-cluster states. However, the FTIR temperature titrations in Ratzloff et al. and Birrell et al. do not suggest vibrational line broadening that could explain the proclaimed 'invisibility' of the $\mu \mathrm{CO}$ ligand at room temperature. ${ }^{122,123}$ Clearly, additional experiments clarifying the influence of temperature is critical moving forward.

Outlook. Thermodynamic considerations exclude H-cluster intermediates with larger structural differences from the catalytic cycle ${ }^{129-131}$, which raised the question whether Hred and Hsred can play a role in the rapid hydrogen turnover of [FeFe]-hydrogenase (Chapter 4). ${ }^{132}$ Today, ambient and cryogenic measurements show both the presence of an additional terminal CO ligand at room temperature ${ }^{110,115,119,121}$ and the presence of a $\mu \mathrm{CO}$ ligand at cryogenic temperature. ${ }^{122-124}$ Moreover, the geometry of Hred and Hsred under ambient conditions is hotly debated, with regards to protonation sites and whether the diiron site adopts an $\mathrm{H}_{2}$ inhibited, $\mu \mathrm{H}$ geometry or an active-ready, Hox-like geometry with a $\mu \mathrm{CO}$ ligand. ${ }^{115}$

In order to understand the interconversion of room temperature and cryogenic species of the $\mathrm{H}$-cluster, it will be important to address the influence of rotational freedom and protein environment as well as proton transfer and proton-coupled electron transport in the 
accumulation and 'shaping' of redox states as a function of temperature. The lack of compatibility between all recent models underscores the inadequate comprehension of hydrogenase catalysis in general. ${ }^{132}$ These considerations are of utmost importance when it comes to the interpretation of crystal structures derived from conventional, cryogenic XRD and spectroscopic investigation in cristallo (Chapter 3.2). Exploiting XFEL radiation to solve the crystal structure of oxidized and reduced [FeFe]-hydrogenase under ambient conditions is an exciting prospect towards a unification of models. Here, it will be important to investigate enzyme with clear preferences for specific redox states, either natural or semi-synthetic [FeFe]hydrogenases (Chapter 2). Moreover, XFELs can be used for serial femtosecond crystallography (SFX) that allows investigating the structure of short-lived, catalytic intermediates. ${ }^{133-135}$ As [FeFe]-hydrogenases are not easily activated, we discuss suitable trigger concepts in the next chapter.

\subsection{Beyond Steady-state Spectroscopy}

Hydrogenases have been characterized by steady-state spectroscopy (Chapters 3.1) and X-ray crystallography (Chapter 3.2). In the case of [FeFe]-hydrogenase, various operando or in situ methods facilitated recording spectral data or activity profiles as a function of electrochemical potential $^{136-138}$, gas composition ${ }^{83}$ and reactant concentration ${ }^{46}$, visible light irradiation, ${ }^{139,140}$ and temperature. ${ }^{122,123}$ While in situ methods typically provide a time resolution between hours and seconds, transient spectroscopy allows following short-lived cofactor intermediates that are difficult to stabilize under steady-state conditions.

UV/vis and IR spectroscopy are well established for the analysis of transient processes in retinal-, porphyrine-, or flavine-binding proteins. ${ }^{141-143}$ This is due to advantageous absorption properties (good signal-to-noise) and the ease of handling visible and infrared light. Here, laser sources are exploited to trigger and trace the natural reactivity of the chromoprotein, i.e. in a 'flash photolysis' setup comprising separate beams (as opposed to ultrafast 'pump/probe' spectroscopy). ${ }^{144,145}$ Hydrogenases lack a dedicated chromophore thus triggering activity is not trivial. To this end, absorption of laser light can be exploited to induce changes in temperature ('T-jump'), $\mathrm{pH}$, or redox potential, the latter in combination with suitable dyes. ${ }^{146-}$ ${ }^{148}$ With the development of tuneable quantum cascade lasers (QCL), a powerful tabletop infrared light source became available that can be exploited as broadband probing light in a flash photolysis-type set-up. ${ }^{144}$ 
Greene et al. reported the first characterization of the soluble [NiFe]-hydrogenase from Pyrococcus furiosus by QCL flash photolysis in the mid-IR. ${ }^{149}$ The authors used either NADH or Cd nanorods (DIR, dot-in-rod) as reductant, transferring an electron to the oxidized hydrogenase upon ionization at $355 \mathrm{~nm}$ or $405 \mathrm{~nm}$, respectively $(\mathbf{N i}-\mathbf{S} \rightarrow \mathbf{N i}-\mathbf{C}) .{ }^{150,151}$ In a complementary approach, Greene et al. addressed the photolability of a catalytic bridging hydride intermediate (Ni-C $\rightarrow \mathbf{N i - S}$ ) at $530 \mathrm{~nm}$, efficiently exploiting the bimetallic cofactor as 'caged proton'. ${ }^{152}$ Theses studies confirmed the kinetic competence of all observed intermediates. In a proof-of-concept study, the first QCL flash photolysis on [FeFe]hydrogenase was reported by Mirmohades et al. in 2016. ${ }^{153}$ Here, the authors followed the rebinding of an inhibiting $\mathrm{CO}$ molecule to the H-cluster of $C r H y d A 1$ after photolysis at $355 \mathrm{~nm}$ $($ Hox $\rightarrow$ Hox-CO) making use of the natural photosensitivity of iron-carbonyl complexes. The kinetics of $\mathrm{CO}$ re-binding were confirmed for several organometallic variants of $\mathrm{CrHydA} 1 .^{83}$ A phototriggered transition from Hox to Hred has been reported for $\mathrm{CaI}$ adsorbed to $\mathrm{Cd}-\mathrm{Se}$ nanocrystals, ${ }^{154}$ revealing a distinct H/D isotope effect that is related to proton-coupled electron transfer. $^{42}$ Pursuing more comprehensively into the catalytic cycle, Greene et al. exploited $\mathrm{NADH}$ as reductant to the electron-bifurcating [FeFe]-hydrogenase from T. maritima (M2f) when activated at $355 \mathrm{~nm} .{ }^{155}$ The transient accumulation of Hsred and Hred' (incorrectly assigned to Hred in the publication) over Hox was found to be compatible with the relatively low turnover frequency of the enzyme $\left(\sim 10 \mathrm{H}_{2} / \mathrm{s}\right) .{ }^{156}$ However, whether these states are relevant to the fast hydrogen turnover of Group A [FeFe]-hydrogenases like $D d \mathrm{H}\left(>1.000 \mathrm{H}_{2} / \mathrm{s}\right)$ remained a matter of speculation. Eventually, Sanchez et al. demonstrated the use of Cd-doped nanorods ${ }^{150,151}$ for the photoreduction of $\mathrm{CrHydA} 1$ via mediated electron transfer (MET) ${ }^{157} \mathrm{~A}$ great variety of redox states were observed, including Hred and Hsred as well as Hred' and Hhyd.

Outlook. As outlined above, numerous states have been identified under steady-state conditions, which inspired the formulation of different mechanistic proposals (Chapter 4). Undoubtedly the next step in mechanistic studies is to investigate the transient catalytic proceedings in $[\mathrm{FeFe}]$-hydrogenase at different temperatures and $\mathrm{pH}$ conditions. This will facilitate a temporal separation of redox states. Based on the data reported by Sanchez et al. ${ }^{157}$, all key redox states (Hred, Hred', Hsred, and Hhyd) may participate in catalytic turnover; however, $\mathrm{pH}$ titrations under both oxidizing and reducing conditions indicate significant differences in the steady-state accumulation of redox states. ${ }^{158}$ Such difference will have an influence on kinetic parameters. Making use of eosin $\mathrm{Y}$ as a photosensitizer facilitates direct 
electron transfer (DET) to the hydrogenase ${ }^{42}$, which may have an effect on the transient kinetics as well. The photoexcitation at $\sim 530 \mathrm{~nm}$ allows using light that does not affect the iron-carbonyl bonds of the H-cluster on short time scales. Cross coupling of hydrogenase molecules to electron relay compounds or redox dyes represents another option to induce DET. ${ }^{159}$ An alternative approach would be addressing the 'natural' photosensitivity of certain redox states, i.e. as shown by Greene $e t$ al. for the bridging hydride intermediate of [NiFe]-hydrogenase ${ }^{152}$ and Lorent et al. for Hred and Hsred of $\mathrm{CrHydA} 1$ at cryogenic temperatures. ${ }^{124}$ In the future, it will be exciting to see how these triggering concepts are utilized in transient UV/vis, FTIR, or X-ray spectroscopy as well as SFX diffraction experiments. Figure 9 summarizes the different trigger concepts discussed and suggested in this chapter.

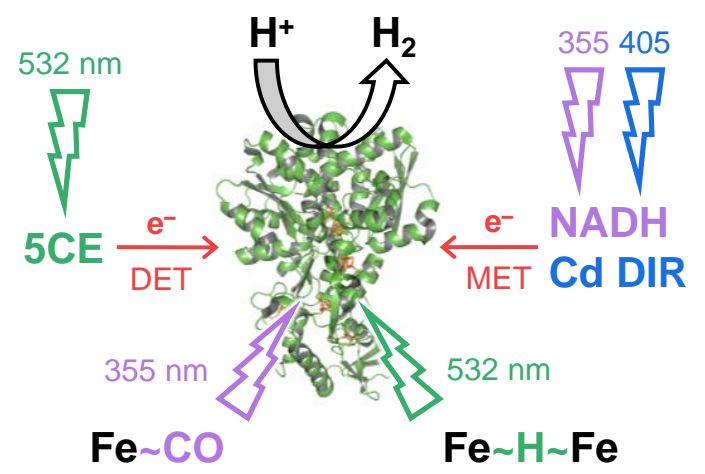

Figure 9 - Triggering hydrogen turnover or catalytic changes by visible light. NADH and Cd-doped nanorods (dot-in-rod, DIR) were used as redox dyes to follow the transient increase and decrease of several [FeFe]hydrogenases redox states. In comparison to mediated electron transfer (MET, e.g. using methyl viologen or bipyridinium groups), direct electron transfer (DET) may influence kinetic parameters, e.g. exploding $5{ }^{`}$-carboxy eosin Y (5CE). Addressing the 'natural' photosensitivity of certain redox states represents an alternative approach. Here, iron-carbonyl or iron-hydride bonds are interrogated by visible light of different color.

\subsection{Biophysical Investigations and Electrochemistry in vivo}

Mössbauer, EPR, and FTIR spectroscopic measurements with a good signal-to-noise ratio demand purified protein samples, often in high concentration and/or larger quantities. However, the properties of purified hydrogenase may deviate from the enzyme in its native environment, and several aspects of hydrogen turnover were first observed in vivo. ${ }^{160}$ In 2010 , Horch et al. reported whole-cell EPR and FTIR spectra of the soluble [NiFe]-hydrogenase from Ralstonia eutropha that helped elucidating the mechanism of $\mathrm{O}_{2}$ tolerance of this particular enzyme. ${ }^{161}$ Similar studies on [FeFe]-hydrogenase were not available until 2017 when Berggren et al. adopted the protocol of artificial maturation ${ }^{56,57}$ to bacterial cells heterologously 
expressing [FeFe]-hydrogenase apo-protein. ${ }^{82,162}$ This paved the way for the first whole-cell EPR study on $C r$ HYDA1 in recombinant $E$. coli cells. ${ }^{163}$
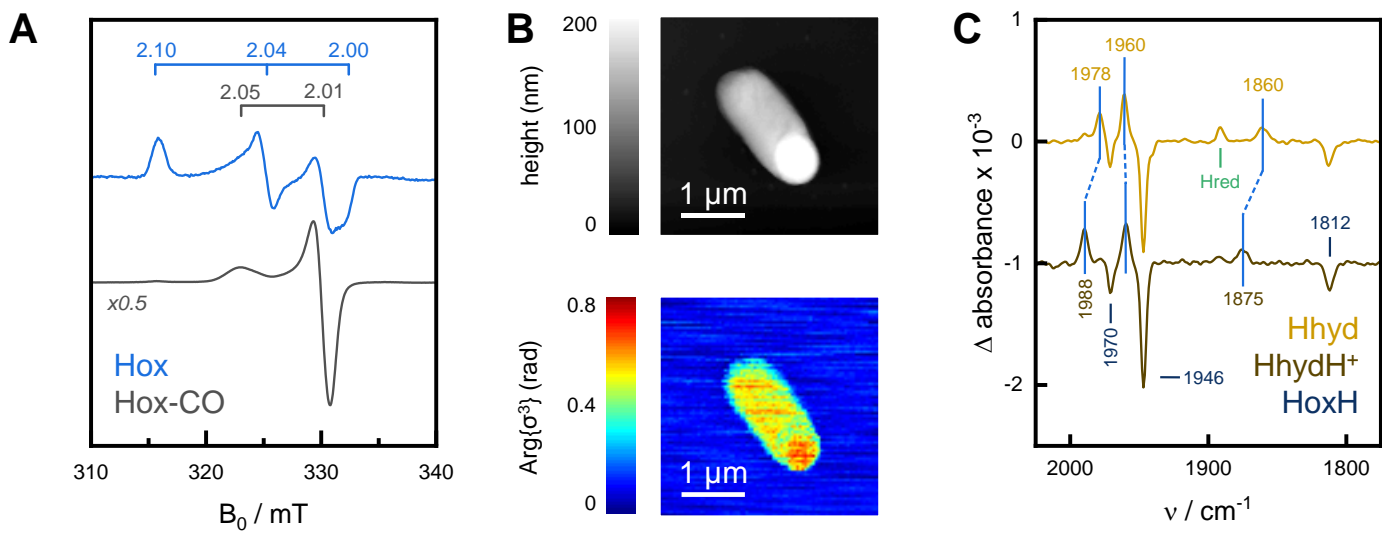

Figure 10 - Biophysical investigations in vivo. (A) Whole-cell EPR spectroscopy under oxidizing conditions in the absence (upper spectrum) and presence of $\mathrm{CO}$ gas (lower spectrum). The signatures of Hox and Hox-CO are clearly detectable. (B) Atomic force microscopy (upper panel) and scattering scanning near-field optical microscopy (sSNOM) on recombinant $E$. coli cells. The sSNOM map was recorded at $1660 \mathrm{~cm}^{-1}$, indicating the lack of protein-specific signal anywhere outside the cell. (C) Whole-cell ATR FTIR difference spectroscopy. At low $\mathrm{pH}$ and in the presence of $\mathrm{H}_{2}$, a pattern characteristic of $\mathbf{H h y d}$ - HoxH (upper spectrum) was observed. When the concentration of dithionite in the sample was increased, $\mathbf{H h y d H}^{+}$was found to be accumulated over $\mathbf{H o x H}$ (lower spectrum).

The paramagnetic states Hox and Hox-CO give relatively unperturbed signals in whole-cell EPR, comparable with purified enzyme (Figure 10). ${ }^{164}$ These signatures have been exploited by Land et al. to screen uncharacterized [FeFe]-hydrogenases in E. coli, circumventing the means of protein purification for preliminary identification and characterization. ${ }^{30}$ Moreover, this study comprises the first whole-cell FTIR evaluation of [FeFe]-hydrogenase, which proved to be challenging due to low signal intensity in the $\mathrm{CO} / \mathrm{CN}^{-}$frequency regime of the $\mathrm{H}$-cluster and significant overlap with water absorption. Investigating the Group D [FeFe]-hydrogenase from Thermoanaerobacter mathranii (M2e), for the first time an EPR-silent reduced H-cluster state (i.e., Hred) could be identified in a living organism. Cell lysates containing catalytically active [FeFe]-hydrogenases like CrHYDA1 and the M2-type [FeFe]-hydrogenase HYDA from Solobacterium moorei (M2) even showed a clear current response in chronoamperometric experiments depending on whether $\mathrm{H}_{2}$ was available for oxidation or not. ${ }^{30}$ Recently, Meszaros et al. used near-field optimal microscopy ( $\mathrm{sSNOM}$ ) to map the protein content of recombinant E. coli cells (Figure 10) ${ }^{111}$ No protein was detected outside the cell bodies indicating that all 
spectroscopic results stem from hydrogenase inside the bacteria. Varying the redox conditions, $\mathrm{pH}$ value, and gas atmosphere, EPR and FTIR spectroscopy verified the formation of reactive hydride states under cellular conditions, including Hhyd as well as a previously incompletely characterized hydride denoted $\mathbf{H h y d H}^{+}$(Figure 10).

Outlook. The first generation of whole-cell biophysical investigations agrees with most measurements performed on purified enzyme. Recombinant hydrogenase was found to react surprisingly fast to changes in buffer, redox potential, $\mathrm{pH}$, and gas composition. H-cluster states Hox, Hred, and Hhyd could be detected in vivo, even under mildly alkaline conditions. ${ }^{111}$ However, elusive species like Hred' and Hsred were barely observed. This is indicative of oxidation and docking to the energy metabolism of host cells, i.e. via the bacterial ferredoxin as demonstrated by Barstow et al. before. ${ }^{165}$ In the future, it will be exciting to study the physiological involvement of hydrogenase in recombinant bacteria and plant cells, e.g. in the context of bifurcation or photosynthesis. ${ }^{162,166}$ Using suitable dyes, fluorescence microscopy could give further insight in $\mathrm{pH}$ changes or $\mathrm{H}_{2}$ release of single cells. ${ }^{167-169}$ Methodically, EPR and FTIR spectroscopy proved to be powerful tools for the analysis of recombinant whole cells. It may be possible to optimize the chemical sensitivity and spatial resolution of near-field techniques to reveal the intracellular location of hydrogenase based on the $\mathrm{CO} / \mathrm{CN}^{-}$signature of the H-cluster. ${ }^{170-173}$ Film electrochemistry on intact $E$. coli cells suffered from low catalytic currents; however, introducing electron relays in the outer membrane may establish electrophysiological measurements of hydrogenase activity.

\section{The Catalytic Mechanism}

In Chapter 2.1.1, we suggested grouping the different [FeFe]-hydrogenases based on their domain architecture (M1 - M5) and phylogenetic relationship (Group A - D). Considering the well-conserved nature of the maturation enzymes (HydEFG), all hydrogenases arguably carry the same H-cluster; however, the presence of up to five F-clusters and deviations in the identity of amino acid residues in proton transfer pathway and active site niche brings forth significant differences in catalytic behavior. Additionally, the advances in artificial maturation allowed exploring variations in cofactor composition beyond the scope of nature (Chapter 2.1.2). These findings form the basis to which speculations on the catalytic proceedings of hydrogen turnover must obey. 
In Chapter 3.1 we introduced the huge variety of electronic intermediates adopted by the $\mathrm{H}$ cluster. While some of these intermediates are rather well understood (Hox, Hred', Hhyd) others show controversial characteristics (Hred, Hsred, Hox-CO). Understanding the controversial states, we suggested combining X-ray diffraction with spectroscopic investigations of crystallized enzyme, e.g. as grown under $\mathrm{H}_{2}$ or adjusted to a certain electrical potential (Chapter 3.2). Further complicating the situation, recent findings demonstrated the influence of temperature on the geometry of the H-cluster. This raised general concerns regarding the relevance of cryogenic methods in understanding [FeFe]-hydrogenase. In Chapter 3.3, we reviewed the key differences between ambient and cryogenic measurements, suggesting diffraction experiments with a XFELs as a powerful technique harvesting structural information under ambient conditions. Besides investigating [FeFe]-hydrogenase with transient spectroscopy methods (Chapter 3.4), serial femtosecond crystallography at XFEL sources may also provide time-resolved structural information.

Based on the wealth of biochemical, structural, and spectroscopic data, different catalytic cycles have been suggested. These are subject to constant evolution; therefore, we refrain from reviewing any details. Figure 11 depicts a simplified catalytic cycle that shows the two main models. Going from A - E in the direction of $\mathrm{H}_{2}$ release, both Birrell et al. and Ratzloff et al. propose the involvement of Hred and Hsred (5-step model). ${ }^{122,123}$ In the first step, Hred' is formed by one-electron reduction of $\mathbf{H o x}(\mathrm{A})$. The charge resides at the [4Fe-4S] cluster. Upon protonation of the adt ligand $\left({ }^{+} \mathrm{NH}_{2}\right)$, it is conceivable that the electron tunnels to the diiron site forming Hred (B). In a second step of one-electron reduction, Hred is converted into Hsred (C). Afterwards, the extra proton at the adt ligand migrates to the open binding site of the distal iron ion and forms Hhyd, formally oxidizing the diiron site by two electrons (D). The reduced [4Fe-4S] cluster stabilizes the 'super-oxidized' diiron site. Upon proton transfer via the adt ligand, the terminal hydride combines to $\mathrm{H}_{2}$, presumably including transient $\mathrm{H}$-cluster states like $\mathbf{H h y d H}^{+}$and Hox-H2 (not shown). ${ }^{124}$ Eventually, release of $\mathrm{H}_{2}$ restores the oxidized resting state Hox (E). 


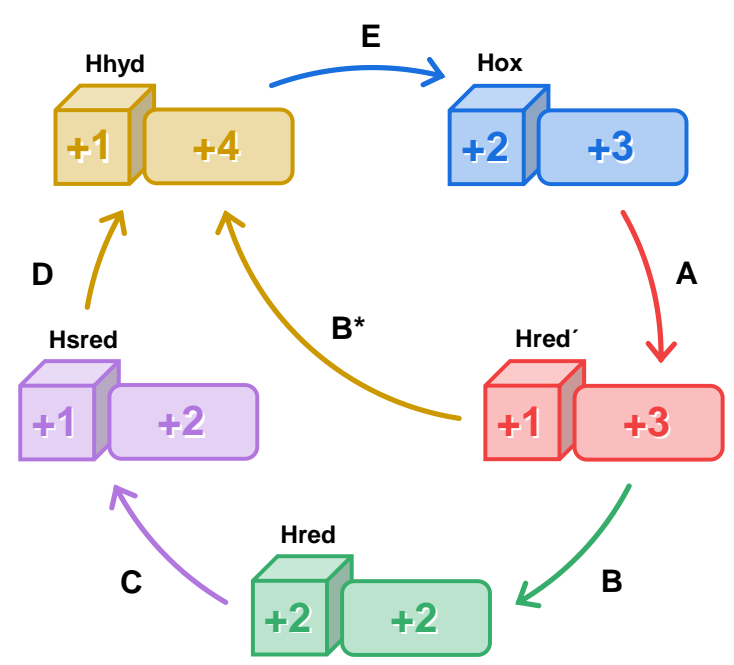

Figure 11 - Possible succession of redox intermediation in biological hydrogen turnover. The 5-step model (A - E) includes Hred and Hsred, presuming the H-cluster retains the $\mu \mathrm{CO}$ ligand upon reduction of the diiron site. The 3-step model (A - B* - E) suggests a 'short-cut' from Hred' to Hhyd as both species share the same geometry. The geometry of Hred and Hsred under ambient conditions is debated. See text for details.

The 5-step model in Figure 11 is based on the interpretation of Hred and Hsred as H-cluster intermediates with an open coordination site at the distal iron ion, not unlike Hox or Hred'. As discussed in Chapter 3.2, this was concluded from the XRD structure of reduced enzyme, showing a 'semi-bridging' CO ligand and no electron density in the terminal position. ${ }^{119}$ However, recent FTIR investigation under cryogenic conditions tempted both Birrell et al. and Ratzloff et al. to propose fully-bridged models for Hred and Hsred (Chapter 3.3). Investigating H-cluster reduction under ambient conditions, Haumann \& Stripp proposed an alternative interpretation of the diiron site geometry in Hred and Hsred. ${ }^{132}$ Here, the presence of a terminal $\mathrm{CO}$ ligand at the distal iron ion alongside stabilization of charge via a bridging hydride species puts Hred and Hsred in the position of ' $\mathrm{H}_{2}$-inhibited' intermediates. ${ }^{83}$ The 3-step model in Figure 11 starts with the conversion of Hox into Hred', including reduction of the [4Fe-4S] cluster and protonation of a coordinating cysteine residue (A). In a second protoncoupled electron transfer step, Hhyd is formed from Hred' directly (B*). Stabilizing the reduced [4Fe-4S] cluster via protonation in both species impedes electrons 'leaking' into the diiron site. ${ }^{46,103,108}$ Dihydrogen release and restoration of Hox is believed to occur in a similar fashion as described above (E). 


\section{Concluding Remarks}

We only just scratched the surface of hydrogenase biodiversity. Moving forward, investigating novel $[\mathrm{FeFe}]$-hydrogenases will help understanding the molecular proceedings of hydrogen turnover. Even less comprehensive is our knowledge about how amino acid patterns shape proton transfer, gas channels, and the dynamic geometry of the H-cluster. While organometallic variants are not likely to enhance catalytic efficiency, interfering with nature will facilitate our comprehension of the inner workings of [FeFe]-hydrogenase. Future experiments must facilitate connections between data collected under ambient or cryogenic conditions, on isolated enzyme or whole cells, and in-between species. Critically, steady-state measurements must also be complemented with transient spectroscopy studies and high-level QM calculations to verify the catalytic relevance of identified states. Fortunately, the community is not shy tackling such problems with novel techniques, e.g. two-dimensional infrared spectroscopy (2DIR), ${ }^{174}$ Fourier-transformed alternating current voltammetry (FTacV $)^{175}$, or scattering-type scanning near-field optimal microscopy (sSNOM). ${ }^{111}$ More will follow, from the biological, chemical, and physical corners of the community, and it will be exciting to participate in the progress.

\section{Acknowledgements}

We would like to thank Prof. Dr. David R. Britt and Dr. Guodong Rao who provided the EPR spectra of Hox and HoxH. The work presented in this article is supported by Novo Nordisk Foundation (grant agreement No. NNF19OC0055613 to HL). Further, this project has received funding from the European Research Council under the European Union's Seventh Framework Programme (grant agreement No. 714102 to GB) and Horizon 2020 research and innovation programme (Marie Sklodowska-Curie grant agreement No. 897555 to MS). Additionally, this project was supported by the Deutsche Forschungsgemeinschaft through the priority program 1927 (grant agreement No. 1554/5-1 to STS).

\section{References}

(1) Marbán, G.; Valdés-Solís, T. Towards the Hydrogen Economy? Int. J. Hydrogen Energy 2007, 32 (12), 1625-1637.

(2) Züttel, A.; Remhof, A.; Borgschulte, A.; Friedrichs, O. Hydrogen: The Future Energy Carrier. Philos. Trans. R. Soc. A Math. Phys. Eng. Sci. 2010, 368 (1923), 3329-3342.

(3) Hosseini, S. E.; Wahid, M. A. Hydrogen Production from Renewable and Sustainable Energy Resources: Promising Green Energy Carrier for Clean Development. Renew. Sustain. Energy Rev. 2016, 57, 850-866. 
(4) Martin, W.; Müller, M. The Hydrogen Hypothesis for the First Eukaryote. Nature 1998, 392, 37-41.

(5) Lubitz, W.; Ogata, H.; Ru, O.; Reijerse, E. Hydrogenases. Chem. Rev. 2014, 114 (8), $4081-4148$.

(6) Madden, C.; Vaughn, M. D.; Díez-Pérez, I.; Brown, K. A.; King, P. W.; Gust, D.; Moore, A. L.; Moore, T. A. Catalytic Turnover of [FeFe]-Hydrogenase Based on Single-Molecule Imaging. J. Am. Chem. Soc. 2011, 143 (3), 1577-1582.

(7) Meyer, J. [FeFe] Hydrogenases and Their Evolution: A Genomic Perspective. Cell. Mol. Life Sci. 2007, 64 (9), 1063-1084.

(8) Calusinska, M.; Happe, T.; Joris, B.; Wilmotte, A. The Surprising Diversity of Clostridial Hydrogenases: A Comparative Genomic Perspective. Microbiology 2010, 156 (6), 1575-1588.

(9) Peters, J. W.; Schut, G. J.; Boyd, E. S.; Mulder, D. W.; Shepard, E. M.; Broderick, J. B.; King, P. W.; Adams, M. W. [FeFe]- and [NiFe]-Hydrogenase Diversity, Mechanism, and Maturation. Biochim. Biophys. Acta 2015, 1853 (6), 1350-1369.

(10) Corr, M. J.; Murphy, J. a. Evolution in the Understanding of [Fe]-Hydrogenase. Chem. Soc. Rev. 2011, 40 (5), 2279-2292.

(11) Benoit, S. L.; Maier, R. J.; Sawers, R. G.; Greening, C. Molecular Hydrogen Metabolism: A Widespread Trait of Pathogenic Bacteria and Protists. Microbiol. Mol. Biol. Rev. 2020, 84 (1), e00092-19.

(12) Peters, J. W.; Lanzilotta, W. N.; Lemon, B. J.; Seefeldt, L. C. X-Ray Crystal Structure of the Fe-Only Hydrogenase $(\mathrm{CpI})$ from Clostridium Pasteurianum to 1.8 Angstrom Resolution. Science 1998, 282 (5395), 1853-1858.

(13) Nicolet, Y.; Piras, C.; Legrand, P.; Hatchikian, C. E.; Fontecilla-Camps, J. C. Desulfovibrio Desulfuricans Iron Hydrogenase: The Structure Shows Unusual Coordination to an Active Site Fe Binuclear Center. Structure 1999, 7 (1), 13-23.

(14) Posewitz, M. C.; King, P. W.; Smolinski, S. L.; Zhang, L.; Seibert, M.; Ghirardi, M. L. Discovery of Two Novel Radical S-Adenosylmethionine Proteins Required for the Assembly of an Active [Fe] Hydrogenase. J. Biol. Chem. 2004, 279 (24), 2571125720 .

(15) King, P. W.; Posewitz, M. C.; Ghirardi, M. L.; Seibert, M. Functional Studies of [FeFe] Hydrogenase Maturation in an Escherichia Coli Biosynthetic System. $J$. Bacteriol. 2006, 188 (6), 2163.

(16) McGlynn, S. E.; Shepard, E. M.; Winslow, M. a; Naumov, A. V; Duschene, K. S.; Posewitz, M. C.; Broderick, W. E.; Broderick, J. B.; Peters, J. W. HydF as a Scaffold Protein in [FeFe] Hydrogenase H-Cluster Biosynthesis. FEBS Lett. 2008, 582 (15), 2183-2187.

(17) Czech, I.; Silakov, A.; Lubitz, W.; Happe, T. The [FeFe]-Hydrogenase Maturase HydF from Clostridium Acetobutylicum Contains a $\mathrm{CO}$ and $\mathrm{CN}$ - Ligated Iron Cofactor. FEBS Lett. 2010, 584 (3), 638-642.

(18) Stephenson, M.; Stickland, L. H. Hydrogenase: A Bacterial Enzyme Activating Molecular Hydrogen: The Properties of the Enzyme. Biochem. J. 1931, 25, 205-214. 
(19) Winkler, M.; Esselborn, J.; Happe, T. Molecular Basis of [FeFe]-Hydrogenase Function: An Insight into the Complex Interplay between Protein and Catalytic Cofactor. Biochim. Biophys. Acta 2013, 1827 (8-9), 974-985.

(20) Vignais, P. M.; Billoud, B.; Meyer, J. Classification and Phylogeny of Hydrogenases. FEMS Microbiol. Rev. 2001, 25, 455-501.

(21) Vignais, P. M.; Billoud, B. Occurrence, Classification, and Biological Function of Hydrogenases: An Overview. Chem. Rev. 2007, 107 (10), 4206-4272.

(22) Greening, C.; Biswas, A.; Carere, C. R.; Jackson, C. J.; Taylor, M. C.; Stott, M. B.; Cook, G. M.; Morales, S. E. Genomic and Metagenomic Surveys of Hydrogenase Distribution Indicate H 2 Is a Widely Utilised Energy Source for Microbial Growth and Survival. ISME J. 2016, 10 (3), 761-777.

(23) Winkler, M.; Hemschemeier, A.; Jacobs, J.; Stripp, S. T.; Happe, T. Multiple Ferredoxin Isoforms in Chlamydomonas Reinhardtii - Their Role under Stress Conditions and Biotechnological Implications. Eur. J. Cell Biol. 2010, 89 (12), 9981004.

(24) Zhang, P.; Yuly, J. L.; Lubner, C. E.; Mulder, D. W.; King, P. W.; Peters, J. W.; Beratan, D. N. Electron Bifurcation: Thermodynamics and Kinetics of Two-Electron Brokering in Biological Redox Chemistry. Acc. Chem. Res. 2017, 50 (9), 2410-2417.

(25) Schuchmann, K.; Chowdhury, N. P.; Müller, V. Complex Multimeric [FeFe] Hydrogenases: Biochemistry, Physiology and New Opportunities for the Hydrogen Economy. Front. Microbiol. 2018, 9 (DEC), 1-22.

(26) Happe, T.; Naber, J. D. Isolation, Characterization and N-Terminal Amino Acid Sequence of Hydrogenase from the Green Alga Chlamydomonas Reinhardtii. Eur. J. Biochem. 1993, 214 (2), 475-481.

(27) Glick, B. R.; Martin, W. G.; Martin, S. M. Purification and Properties of the Periplasmatic Hydrogenase from Desulfovibrio Desulfuricans. Can. J. Microbiol. 1980, 26 (10), 1214-1223.

(28) Nakos, G.; Mortenson, L. Purification and Properties of Hydrogenase, an Iron Sulfur Protein, from Clostridium Pasteurianum W5. Biochim. Biophys. Acta 1971, 227 (10), 576-583.

(29) Chongdar, N.; Birrell, J. A.; Pawlak, K.; Sommer, C.; Reijerse, E. J.; Rüdiger, O.; Lubitz, W.; Ogata, H. Unique Spectroscopic Properties of the H-Cluster in a Putative Sensory [FeFe] Hydrogenase. J. Am. Chem. Soc. 2018, 140 (3), 1057-1068.

(30) Land, H.; Ceccaldi, P.; Mészáros, L. S.; Lorenzi, M.; Redman, H. J.; Senger, M.; Stripp, S. T.; Berggren, G. Discovery of Novel [FeFe]-Hydrogenases for Biocatalytic H2-Production. Chem. Sci. 2019, 10 (43), 9941-9948.

(31) Gauquelin, C.; Baffert, C.; Richaud, P.; Kamionka, E.; Etienne, E.; Guieysse, D.; Girbal, L.; Fourmond, V.; André, I.; Guigliarelli, B.; et al. Roles of the F-Domain in [FeFe] Hydrogenase. Biochim. Biophys. Acta - Bioenerg. 2018, 1859 (2), 69-77.

(32) Caserta, G.; Papini, C.; Adamska-Venkatesh, A.; Pecqueur, L.; Sommer, C.; Reijerse, E.; Lubitz, W.; Gauquelin, C.; Meynial-Salles, I.; Pramanik, D.; et al. Engineering an [FeFe]-Hydrogenase: Do Accessory Clusters Influence O2 Resistance and Catalytic Bias? J. Am. Chem. Soc. 2018, 140 (16), 5516-5526. 
(33) Rodríguez-Maciá, P.; Pawlak, K.; Rüdiger, O.; Reijerse, E. J.; Lubitz, W.; Birrell, J. A. Intercluster Redox Coupling Influences Protonation at the H-Cluster in [FeFe] Hydrogenases. J. Am. Chem. Soc. 2017, 139 (42), 15122-15134.

(34) Artz, J. H.; Mulder, D. W.; Ratzloff, M. W.; Lubner, C. E.; Zadvornyy, O. A.; Levan, A. X.; Williams, S. G.; Adams, M. W. W.; Jones, A. K.; King, P. W.; et al. Reduction Potentials of [FeFe]-Hydrogenase Accessory Iron-Sulfur Clusters Provide Insights into the Energetics of Proton Reduction Catalysis. J. Am. Chem. Soc. 2017, 139 (28), 95449550.

(35) Cohen, J.; Kim, K.; King, P. W.; Seibert, M.; Schulten, K. Finding Gas Diffusion Pathways in Proteins: Application to O2 and H2 Transport in CpI [FeFe]-Hydrogenase and the Role of Packing Defects. Structure 2005, 13 (9), 1321-1329.

(36) Kubas, A.; Orain, C.; Sancho, D. De; Saujet, L.; Sensi, M.; Gauquelin, C.; Meynialsalles, I.; Soucaille, P.; Bottin, H.; Baffert, C.; et al. Mechanism of O2 Diffusion and Reduction in FeFe Hydrogenases. Nat. Chem. 2017, 9, 88-95.

Lautier, T.; Ezanno, P.; Baffert, C.; Fourmond, V.; Cournac, L.; Fontecilla-Camps, J. C.; Soucaille, P.; Bertrand, P.; Meynial-Salles, I.; Léger, C. The Quest for a Functional Substrate Access Tunnel in FeFe Hydrogenase. Faraday Discuss. 2011, 148, 385.

(38) Cornish, A. J.; Gärtner, K.; Yang, H.; Peters, J. W.; Hegg, E. L. Mechanism of Proton Transfer in [FeFe]-Hydrogenase from Clostridium Pasteurianum. J. Biol. Chem. 2011, $19,38341-38347$.

(39) Morra, S.; Giraudo, A.; Di Nardo, G.; King, P. W.; Gilardi, G.; Valetti, F. Site Saturation Mutagenesis Demonstrates a Central Role for Cysteine 298 as Proton Donor to the Catalytic Site in CaHydA [FeFe]-Hydrogenase. PLoS One 2012, 7 (10), e48400.

(40) Cornish, A. J.; Ginovska, B.; Thelen, A.; Da Silva, J. C. S.; Soares, T. A.; Raugei, S.; Dupuis, M.; Shaw, W. J.; Hegg, E. L. Single-Amino Acid Modifications Reveal Additional Controls on the Proton Pathway of [FeFe]-Hydrogenase. Biochemistry 2016, 55 (22), 3165-3173.

(41) Duan, J.; Senger, M.; Esselborn, J.; Engelbrecht, V.; Wittkamp, F.; Apfel, U.-P.; Hofmann, E.; Stripp, S. T.; Happe, T.; Winkler, M. Crystallographic and Spectroscopic Assignment of the Proton Transfer Pathway in [FeFe]-Hydrogenases. Nat. Commun. 2018, 9, 4726.

(42) Senger, M.; Eichmann, V.; Laun, K.; Duan, J.; Wittkamp, F.; Knör, G.; Apfel, U.-P.; Happe, T.; Winkler, M.; Heberle, J.; et al. How [FeFe]-Hydrogenase Facilitates Bidirectional Proton Transfer. J. Am. Chem. Soc. 2019, 141 (43), 17394-17403.

(43) Knörzer, P.; Silakov, A.; Foster, C. E.; Armstrong, F. A.; Lubitz, W.; Happe, T. Importance of the Protein Framework for Catalytic Activity of [FeFe]-Hydrogenases. J. Biol. Chem. 2012, 287 (2), 1489-1499.

(44) Lampret, O.; Adamska-Venkatesh, A.; Konegger, H.; Wittkamp, F.; Apfel, U.-P.; Reijerse, E. J.; Lubitz, W.; Rüdiger, O.; Happe, T.; Winkler, M. Interplay between CN Ligands and the Secondary Coordination Sphere of the H-Cluster in [FeFe]Hydrogenases. J. Am. Chem. Soc. 2017, 139 (50), 18222-18230.

(45) Kertess, L.; Adamska-Venkatesh, A.; Rodríguez-Maciá, P.; Rüdiger, O.; Lubitz, W.; Happe, T. Influence of the $[4 \mathrm{Fe}-4 \mathrm{~S}]$ Cluster Coordinating Cysteines on Active Site 
Maturation and Catalytic Properties of C. Reinhardtii [FeFe]-Hydrogenase. Chem. Sci. 2017, 8 (12), 8127-8137.

(46) Senger, M.; Mebs, S.; Duan, J.; Shulenina, O.; Laun, K.; Kertess, L.; Wittkamp, F.; Apfel, U.-P.; Happe, T.; Winkler, M.; et al. Protonation/Reduction Dynamics at the [4Fe-4S] Cluster of the Hydrogen-Forming Cofactor in [FeFe]-Hydrogenases. Phys. Chem. Chem. Phys. 2018, 20, 3128-3140.

(47) Artz, J. H.; Zadvornyy, O. A.; Mulder, D. W.; Keable, S. M.; Cohen, A. E.; Ratzloff, M. W.; Williams, S. G.; Ginovska, B.; Kumar, N.; Song, J.; et al. Tuning Catalytic Bias of Hydrogen Gas Producing Hydrogenases. J. Am. Chem. Soc. 2020, 142, 1227-1235.

(48) Shug, A. L.; Wilson, P. W.; Green, D. E.; Mahler, H. R. The Role of Molybdenum and Flavin in Hydrogenase. J. Am. Chem. Soc. 1954, 76 (12), 3355-3356.

(49) Kaur, J.; Kumar, A.; Kaur, J. Strategies for Optimization of Heterologous Protein Expression in E. Coli: Roadblocks and Reinforcements. Int. J. Biol. Macromol. 2017, $106,803-822$.

(50) Ahmad, M.; Hirz, M.; Pichler, H.; Schwab, H. Protein Expression in Pichia Pastoris: Recent Achievements and Perspectives for Heterologous Protein Production. Appl. Microbiol. Biotechnol. 2014, 98 (12), 5301-5317.

(51) Akhtar, M. K.; Jones, P. R. Deletion of IscR Stimulates Recombinant Clostridial Fe-Fe Hydrogenase Activity and H2-Accumulation in Escherichia Coli BL21(DE3). Appl. Microbiol. Biotechnol. 2008, 78 (5), 853-862.

(52) Kuchenreuther, J. M.; Grady-Smith, C. S.; Bingham, A. S.; George, S. J.; Cramer, S. P.; Swartz, J. R. High-Yield Expression of Heterologous [FeFe] Hydrogenases in Escherichia Coli. PLoS One 2010, 5 (11).

(53) Girbal, L.; Von Abendroth, G.; Winkler, M.; Benton, P.; Meynial-Salles, I.; Croux, C.; Peters, J. W.; Happe, T.; Soucaille, P. Homologous and Heterologous Overexpression in Clostridium Acetobutylicum and Characterization of Purified Clostridial and Algal Fe-Only Hydrogenases with High Specific Activities. Appl. Environ. Microbiol. 2005, 71 (5), 2777-2781.

(54) von Abendroth, G.; Stripp, S. T.; Silakov, A.; Croux, C.; Soucaille, P.; Girbal, L.; Happe, T. Optimized Over-Expression of [FeFe] Hydrogenases with High Specific Activity in Clostridium Acetobutylicum. Int. J. Hydrogen Energy 2008, 33 (21), 60766081 .

(55) Sybirna, K.; Antoine, T.; Lindberg, P.; Fourmond, V.; Rousset, M.; Méjean, V.; Bottin, H. Shewanella Oneidensis: A New and Efficient System for Expression and Maturation of Heterologous [Fe-Fe] Hydrogenase from Chlamydomonas Reinhardtii. BMC Biotechnol. 2008, 8, 73.

(56) Berggren, G.; Adamska-Venkatesh, A.; Lambertz, C.; Simmons, T. R.; Esselborn, J.; Atta, M.; Gambarelli, S.; Mouesca, J.-M.; Reijerse, E. J.; Lubitz, W.; et al. Biomimetic Assembly and Activation of [FeFe]-Hydrogenases. Nature 2013, 499 (7456), 66-69.

(57) Esselborn, J.; Lambertz, C.; Adamska-Venkatesh, A.; Simmons, T.; Berggren, G.; Noth, J.; Siebel, J. F.; Hemschemeier, A.; Artero, V.; Reijerse, E.; et al. Spontaneous Activation of [FeFe]-Hydrogenases by an Inorganic [2Fe] Active Site Mimic. Nat. 
Chem. Biol. 2013, 9, 607-609.

(58) Bornscheuer, U. T.; Huisman, G. W.; Kazlauskas, R. J.; Lutz, S.; Moore, J. C.; Robins, K. Engineering the Third Wave of Biocatalysis. Nature 2012, 485 (7397), 185-194.

(59) Hatchikian, E. C.; Forget, N.; Fernandez, V. M.; Williams, R.; Cammack, R. Further Characterization of the [Fe]-Hydrogenase from Desulfovibrio Desulfuricans ATCC 7757. Eur. J. Biochem. 1992, 209 (1), 357-365.

(60) Caserta, G.; Adamska-Venkatesh, A.; Pecqueur, L.; Atta, M.; Artero, V.; Roy, S.; Reijerse, E.; Lubitz, W.; Fontecave, M. Chemical Assembly of Multiple Metal Cofactors: The Heterologously Expressed Multidomain [FeFe]-Hydrogenase from Megasphaera Elsdenii. Biochim. Biophys. Acta - Bioenerg. 2016, 1857 (11), 17341740 .

(61) Engelbrecht, V.; Rodríguez-Maciá, P.; Esselborn, J.; Sawyer, A.; Hemschemeier, A.; Rüdiger, O.; Lubitz, W.; Winkler, M.; Happe, T. The Structurally Unique Photosynthetic Chlorella Variabilis NC64A Hydrogenase Does Not Interact with Plant-Type Ferredoxins. Biochim. Biophys. Acta - Bioenerg. 2017, 1858 (9), 771-778.

(62) Morra, S.; Arizzi, M.; Valetti, F.; Gilardi, G. Oxygen Stability in the New [FeFe]Hydrogenase from Clostridium Beijerinckii SM10 (CbA5H). Biochemistry 2016, 55 (42), 5897-5900.

(63) Ruff, A.; Conzuelo, F.; Schuhmann, W. Bioelectrocatalysis as the Basis for the Design of Enzyme-Based Biofuel Cells and Semi-Artificial Biophotoelectrodes. Nat. Catal. 2019.

(64) Mulder, D. W.; Ortillo, D. O.; Gardenghi, D. J.; Naumov, A. V.; Ruebush, S. S.; Szilagyi, R. K.; Huynh, B.; Broderick, J. B.; Peters, J. W. Activation of HydA(DeltaEFG) Requires a Preformed [4Fe-4S] Cluster. Biochemistry 2009, 48, 6240-6248.

(65) Mulder, D. W.; Boyd, E. S.; Sarma, R.; Lange, R. K.; Endrizzi, J. A.; Broderick, J. B.; Peters, J. W. Stepwise [FeFe]-Hydrogenase H-Cluster Assembly Revealed in the Structure of HydA(DeltaEFG). Nature 2010, 465 (7295), 248-251.

(66) Caserta, G.; Pecqueur, L.; Adamska-Venkatesh, A.; Papini, C.; Roy, S.; Artero, V.; Atta, M.; Reijerse, E.; Lubitz, W.; Fontecave, M. Structural and Functional Characterization of the Hydrogenase-Maturation HydF Protein. Nat. Chem. Biol. 2017, 13 (7), 779-784.

(67) Rao, G.; Pattenaude, S. A.; Alwan, K.; Blackburn, N. J.; Britt, R. D.; Rauchfuss, T. B. The Binuclear Cluster of [FeFe] Hydrogenase Is Formed with Sulfur Donated by Cysteine of an $[\mathrm{Fe}(\mathrm{Cys})(\mathrm{CO}) 2(\mathrm{CN})]$ Organometallic Precursor. Proc. Natl. Acad. Sci. U. S. A. 2019, 116 (42), 20850-20855.

(68) Németh, B.; Esmieu, C.; Redman, H. J.; Berggren, G. Monitoring H-Cluster Assembly Using a Semi-Synthetic HydF Protein. Dalt. Trans. 2019, 48 (18), 5978-5986.

(69) Chongdar, N.; Pawlak, K.; Rüdiger, O.; Reijerse, E. J.; Rodríguez-Maciá, P.; Lubitz, W.; Birrell, J. A.; Ogata, H. Spectroscopic and Biochemical Insight into an ElectronBifurcating [FeFe] Hydrogenase. J. Biol. Inorg. Chem. 2019, 24, in press.

(70) Gilbert-Wilson, R.; Siebel, J. F.; Adamska-Venkatesh, A.; Pham, C. C.; Reijerse, E.; Wang, H.; Cramer, S. P.; Lubitz, W.; Rauchfuss, T. B. Spectroscopic Investigations of 
[FeFe] Hydrogenase Maturated with [57Fe2(Adt)(CN)2(CO)4]2-. J. Am. Chem. Soc. 2015, 137 (28), 8998-9005.

(71) Adamska-Venkatesh, A.; Simmons, T. R.; Siebel, J. F.; Artero, V.; Fontecave, M.; Lubitz, W. Chlamydomonas Reinhardtii: HYSCORE and ENDOR Study of a NonNatural H-Cluster. Phys. Chem. Chem. Phys. 2015, 17, 5421-5430.

(72) Adamska-Venkatesh, A.; Roy, S.; Siebel, J. F.; Simmons, T. R.; Fontecave, M.; Artero, V.; Reijerse, E.; Lubitz, W. Spectroscopic Characterization of the Bridging Amine in the Active Site of [FeFe] Hydrogenase Using Isotopologues of the HCluster. J. Am. Chem. Soc. 2015, 137 (40), 12744-12747.

(73) Artero, V.; Berggren, G.; Atta, M.; Caserta, G.; Roy, S.; Pecqueur, L.; Fontecave, M. From Enzyme Maturation to Synthetic Chemistry: The Case of Hydrogenases. Acc. Chem. Res. 2015, 48 (8), 2380-2387.

(74) Birrell, J. A.; Rüdiger, O.; Reijerse, E. J.; Lubitz, W. Semisynthetic Hydrogenases Propel Biological Energy Research into a New Era. Joule 2017, 1 (1), 61-76.

(75) Esmieu, C.; Raleiras, P.; Berggren, G. From Protein Engineering to Artificial Enzymes-Biological and Biomimetic Approaches towards Sustainable Hydrogen Production. Sustain. Energy Fuels 2018, 2 (4), 724-750.

(76) Wittkamp, F.; Senger, M.; Stripp, S. T.; Apfel, U.-P. [FeFe]-Hydrogenases: Recent Developments and Future Perspectives. Chem. Commun. 2018, 54, 5934-5942.

(77) Sommer, C.; Richers, C. P.; Lubitz, W.; Rauchfuss, T. B.; Reijerse, E. J. A [RuRu] Analogue of an $[\mathrm{FeFe}]-H y d r o g e n a s e$ Traps the Key Hydride Intermediate of the Catalytic Cycle Angewandte. Angew. Chemie Int. Ed. 2018, 57, 5429 -5432.

(78) Noth, J.; Esselborn, J.; Güldenhaupt, J.; Brünje, A.; Sawyer, A.; Apfel, U.-P.; Gerwert, K.; Hofmann, E.; Winkler, M.; Happe, T. [FeFe]-Hydrogenase with Chalcogenide Substitutions at the H-Cluster Maintains Full H2 Evolution Activity. Angew. Chemie Int. Ed. 2016, 55, 8396-8400.

(79) Kertess, L.; Wittkamp, F.; Sommer, C.; Esselborn, J.; Rüdiger, O.; Reijerse, E.; Hofmann, E.; Lubitz, W.; Winkler, M.; Happe, T.; et al. Chalcogenide Substitution in the [2Fe]-Cluster of [FeFe]-Hydrogenases Conserves High Enzymatic Activity. Dalt. Trans. 2017, 46, 16947-16958.

(80) Siebel, J. F.; Adamska-Venkatesh, A.; Weber, K.; Rumpel, S.; Reijerse, E.; Lubitz, W. Hybrid [FeFe]-Hydrogenases with Modified Active Sites Show Remarkable Residual Enzymatic Activity. Biochemistry 2015, 54 (7), 1474-1483.

(81) Esselborn, J.; Muraki, N.; Klein, K.; Engelbrecht, V.; Metzler-Nolte, N.; Apfel, U.-P.; Hofmann, E.; Kurisu, G.; Happe, T. A Structural View of Synthetic Cofactor Integration into [FeFe]-Hydrogenases. Chem. Sci. 2016, 7, 959-968.

(82) Khanna, N.; Esmieu, C.; Mészáros, L. S.; Lindblad, P.; Berggren, G. In Vivo Activation of an $[\mathrm{FeFe}]$ Hydrogenase Using Synthetic Cofactors. Energy Environ. Sci. 2017, 10 (7), 1563-1567.

(83) Duan, J.; Mebs, S.; Laun, K.; Wittkamp, F.; Heberle, J.; Hofmann, E.; Apfel, U.-P.; Winkler, M.; Senger, M.; Haumann, M.; et al. Geometry of the Catalytic Active Site in [FeFe]-Hydrogenase Is Determined by Hydrogen Bonding and Proton Transfer. ACS Catal. 2019, 9, 9140-9149. 
(84) Tard, C.; Pickett, C. J. Structural and Functional Analogues of the Active Sites of the [Fe]-, [NiFe]-, and [FeFe]-Hydrogenases. Chem. Rev. 2009, 109 (6), 2245-2274.

(85) Simmons, T. R.; Berggren, G.; Bacchi, M.; Fontecave, M.; Artero, V. Mimicking Hydrogenases: From Biomimetics to Artificial Enzymes. Coord. Chem. Rev. 2014, 270-271 (1), 127-150.

(86) Schilter, D.; Camara, J. M.; Huynh, M. T.; Hammes-Schiffer, S.; Rauchfuss, T. B. Hydrogenase Enzymes and Their Synthetic Models: The Role of Metal Hydrides. Chem. Rev. 2016, 116 (15), 8693-8749.

(87) Camara, J. M.; Rauchfuss, T. B. Combining Acid-Base, Redox and Substrate Binding Functionalities to Give a Complete Model for the [FeFe]-Hydrogenase. Nat. Chem. 2012, 4 (1), 26-30.

(88) Esmieu, C.; Guo, M.; Redman, H. J.; Lundberg, M.; Berggren, G. Synthesis of a Miniaturized [FeFe] Hydrogenase Model System. Dalt. Trans. 2019, 48 (7), 22802284.

(89) Brezinski, W. P.; Karayilan, M.; Clary, K. E.; Pavlopoulos, N. G.; Li, S.; Fu, L.; Matyjaszewski, K.; Evans, D. H.; Glass, R. S.; Lichtenberger, D. L.; et al. [FeFe]Hydrogenase Mimetic Metallopolymers with Enhanced Catalytic Activity for Hydrogen Production in Water. Angew. Chemie - Int. Ed. 2018, 57 (37), 11898-11902.

(90) Karayilan, M.; Brezinski, W. P.; Clary, K. E.; Lichtenberger, D. L.; Glass, R. S.; Pyun, J. Catalytic Metallopolymers from [2Fe-2S] Clusters: Artificial Metalloenzymes for Hydrogen Production. Angew. Chemie - Int. Ed. 2019, 58 (23), 7537-7550.

(91) Popescu, C.; Münck, E. Electronic Structure of the H Cluster in [FeFe]-Hydrogenases. J. Am. Chem. Soc. 1999, No. 5, 15054-15061.

(92) Pereira, A. S. S.; Tavares, P.; Moura, I.; Moura, J. J. G. J.; Huynh, B. H. H. Mössbauer Characterization of the Iron-Sulfur Clusters in Desulfovibrio v Ulgaris Hydrogenase. $J$. Am. Chem. Soc. 2001, 123 (12), 2771-2782.

(93) Silakov, A.; Reijerse, E. J.; Albracht, S. P. J.; Hatchikian, E. C.; Lubitz, W. The Electronic Structure of the H-Cluster in the [FeFe]-Hydrogenase from Desulfovibrio Desulfuricans: A Q-Band 57Fe-ENDOR and HYSCORE Study. J. Am. Chem. Soc. 2007, 129 (37), 11447-11458.

(94) Lubitz, W.; Reijerse, E.; van Gastel, M. [NiFe] and [FeFe] Hydrogenases Studied by Advanced Magnetic Resonance Techniques. Chem. Rev. 2007, 107 (10), 4331-4365.

(95) Telser, J.; Benecky, M. J.; Adams, M. W. W.; Mortenson, L. E.; Hoffman, B. M. An EPR and Electron Nuclear Double Resonance Investigation of Carbon Monoxide Binding to Hydrogenase I (Bidirectional) from Clostridium Pasteurianum W5. J. Biol. Chem. 1986, 261 (29), 13536-13541.

(96) Telser, J.; Benecky, M. J.; Adams, M. W.; Mortenson, L. E.; Hoffman, B. M. EPR and Electron Nuclear Double Resonance Investigation of Oxidized Hydrogenase II (Uptake) from Clostridium Pasteurianum W5. Effects of Carbon Monoxide Binding. $J$. Biol. Chem. 1987, 262 (14), 6589-6594.

(97) Silakov, A.; Wenk, B.; Reijerse, E.; Lubitz, W. 14N HYSCORE Investigation of the H-Cluster of [FeFe] Hydrogenase: Evidence for a Nitrogen in the Dithiol Bridge. Phys. Chem. Chem. Phys. 2009, 11 (31), 6553-6554. 
(98) Albracht, S. P. J.; Roseboom, W.; Hatchikian, E. C. The Active Site of the [FeFe]Hydrogenase from Desulfovibrio Desulfuricans. I. Light Sensitivity and Magnetic Hyperfine Interactions as Observed by Electron Paramagnetic Resonance. J. Biol. Inorg. Chem. 2006, 11 (1), 88-101.

(99) Adamska-Venkatesh, A.; Silakov, A.; Lambertz, C.; Rüdiger, O.; Happe, T.; Reijerse, E.; Lubitz, W. Identification and Characterization of the "Super-Reduced" State of the $\mathrm{H}-\mathrm{Cl}$ uster in [FeFe] Hydrogenase: A New Building Block for the Catalytic Cycle? Angew. Chemie Int. Ed. 2012, 51 (46), 11458-11462.

(100) Adamska-Venkatesh, A.; Krawietz, D.; Siebel, J. F.; Weber, K.; Happe, T.; Reijerse, E.; Lubitz, W. New Redox States Observed in [FeFe] Hydrogenases Reveal Redox Coupling within the H-Cluster. J. Am. Chem. Soc. 2014, 136 (32), 11339-11346.

(101) Mulder, D. W.; Ratzloff, M. W.; Bruschi, M.; Greco, C.; Koonce, E.; Peters, J. W.; King, P. W. Investigations on the Role of Proton-Coupled Electron Transfer in Hydrogen Activation by [FeFe]-Hydrogenase. J. Am. Chem. Soc. 2014, 136 (43), 15394-15402.

(102) Mulder, D. W.; Guo, Y.; Ratzloff, M. W.; King, P. W. Identification of a Catalytic Iron-Hydride at the H-Cluster of [FeFe]-Hydrogenase. J. Am. Chem. Soc. 2016, 139 (1), 83-86.

(103) Winkler, M.; Senger, M.; Duan, J.; Esselborn, J.; Wittkamp, F.; Hofmann, E.; Apfel, U.-P.; Stripp, S. T.; Happe, T. Accumulating the Hydride State in the Catalytic Cycle of [FeFe]-Hydrogenases. Nat. Commun. 2017, 8 (16115), 1-7.

(104) Reijerse, E. J.; Pham, C. C.; Pelmenschikov, V.; Gilbert-wilson, R.; AdamskaVenkatesh, A.; Siebel, J. F.; Gee, L. B.; Yoda, Y.; Tamasaku, K.; Lubitz, W.; et al. Direct Observation of an Iron-Bound Terminal Hydride in [FeFe]- Hydrogenase by Nuclear Resonance Vibrational Spectroscopy. J. Am. Chem. Soc. 2017, 139 (12), 4306-4309.

(105) Pierik, A. J.; Hulstein, M.; Hagen, W. R.; Albracht, S. P. A Low-Spin Iron with CN and $\mathrm{CO}$ as Intrinsic Ligands Forms the Core of the Active Site in [Fe]-Hydrogenases. Eur. J. Biochem. 1998, 258 (2), 572-578.

(106) Pierik, A. J.; Roseboom, W.; Happe, R. P.; Bagley, K. A.; Albracht, S. P. J. Carbon Monoxide and Cyanide as Intrinsic Ligands to Iron in the Active Site of [NiFe]Hydrogenases. J. Biol. Chem. 1999, 274 (6), 3331-3337.

(107) De Lacey, A. L.; Stadler, C.; Cavazza, C.; Hatchikian, E. C.; Fernandez, V. M. FTIR Characterization of the Active Site of the Fe-Hydrogenase from Desulfovibrio Desulfuricans. J. Am. Chem. Soc. 2000, 122 (45), 11232-11233.

(108) Senger, M.; Laun, K.; Wittkamp, F.; Duan, J.; Haumann, M.; Happe, T.; Winkler, M.; Apfel, U.-P.; Stripp, S. T. Proton-Coupled Reduction of the Catalytic [4Fe-4S] Cluster in [FeFe]-Hydrogenases. Angew. Chemie Int. Ed. 2017, 56 (52), 16503-16506.

(109) Katz, S.; Noth, J.; Horch, M.; Shafaat, H. S.; Happe, T.; Hildebrandt, P.; Zebger, I. Vibrational Spectroscopy Reveals the Initial Steps of Biological Hydrogen Evolution. Chem. Sci. 2016, 7, 6746-6752.

(110) Roseboom, W.; De Lacey, A. L.; Fernandez, V. M.; Hatchikian, E. C.; Albracht, S. P. J. The Active Site of the [FeFe]-Hydrogenase from Desulfovibrio Desulfuricans. II. 
Redox Properties, Light Sensitivity and CO-Ligand Exchange as Observed by Infrared Spectroscopy. J. Biol. Inorg. Chem. 2006, 11 (1), 102-118.

(111) Mészáros, L. S.; Ceccaldi, P.; Lorenzi, M.; Redman, H. J.; Pfitzner, E.; Heberle, J.; Senger, M.; Stripp, S. T.; Berggren, G. Spectroscopic Investigations under Whole Cell Conditions Provide New Insight into the Metal Hydride Chemistry of [FeFe]Hydrogenase. ChemRxiv 2020, preprint.

(112) Senger, M.; Mebs, S.; Duan, J.; Wittkamp, F.; Apfel, U.-P.; Heberle, J.; Haumann, M.; Stripp, S. T. Stepwise Isotope Editing of [FeFe]-Hydrogenases Exposes Cofactor Dynamics. Proc. Natl. Acad. Sci. U. S. A. 2016, 113 (30), 8454-8459.

(113) Zilberman, S.; Stiefel, E. I.; Cohen, M. H.; Car, R. Resolving the CO / CN Ligand Arrangement in CO-Inactivated [FeFe] Hydrogenase by First Principles Density Functional Theory Calculations. Inorg. Chem. 2006, 45 (15), 5715-5717.

(114) Laun, K.; Mebs, S.; Duan, J.; Wittkamp, F.; Apfel, U.-P.; Happe, T.; Winkler, M.; Haumann, M.; Stripp, S. T. Spectroscopical Investigations on the Redox Chemistry of [FeFe]-Hydrogenases in the Presence of Carbon Monoxide. MOLECULES 2018, 23 (7), 1669.

(115) Mebs, S.; Senger, M.; Duan, J.; Wittkamp, F.; Apfel, U.-P.; Happe, T.; Winkler, M.; Stripp, S. T.; Haumann, M. Bridging Hydride at Reduced H-Cluster Species in [FeFe]Hydrogenases Revealed by Infrared Spectroscopy, Isotope Editing, and Quantum Chemistry. J. Am. Chem. Soc. 2017, 139 (35), 12157-12160.

(116) Lemon, B. J.; Peters, J. W. Binding of Exogenously Added Carbon Monoxide at the Active Site of the Iron-Only Hydrogenase (CpI) from Clostridium Pasteurianum. Biochemistry 1999, 38 (40), 12969-12973.

(117) Bennett, B.; Lemon, B. J.; Peters, J. W. Reversible Carbon Monoxide Binding and Inhibition at the Active Site of the Fe-Only Hydrogenase. Biochemistry 2000, 39 (25), $7455-7460$.

(118) Lemon, B. J.; Peters, J. W. Photochemistry at the Active Site of the Carbon Monoxide Inhibited Form of the Iron-Only Hydrogenase (CpI). J. Am. Chem. Soc. 2000, 122 (15), 3793-3794.

(119) Nicolet, Y.; De Lacey, A. L.; Vernède, X.; Fernandez, V. M.; Hatchikian, E. C.; Fontecilla-Camps, J. C. Crystallographic and FTIR Spectroscopic Evidence of Changes in Fe Coordination upon Reduction of the Active Site of the Fe-Only Hydrogenase from Desulfovibrio Desulfuricans. J. Am. Chem. Soc. 2001, 123 (8), 1596-1601.

(120) Fourmond, V.; Greco, C.; Sybirna, K.; Baffert, C.; Wang, P.-H.; Ezanno, P.; Montefiori, M.; Bruschi, M.; Meynial-Salles, I.; Soucaille, P.; et al. The Oxidative Inactivation of FeFe Hydrogenase Reveals the Flexibility of the H-Cluster. Nat. Chem. 2014, 6 (4), 336-342.

(121) Sommer, C.; Adamska-Venkatesh, A.; Pawlak, K.; Birrell, J. A.; Rüdiger, O.; Reijerse, E. J.; Lubitz, W. Proton Coupled Electronic Rearrangement within the H-Cluster as an Essential Step in the Catalytic Cycle of [FeFe] Hydrogenases. J. Am. Chem. Soc. 2017, 139 (4), 1440-1443.

(122) Ratzloff, M. W.; Artz, J. H.; Mulder, D. W.; Collins, R. T.; Furtak, T. E.; King, P. W. 
CO-Bridged H-Cluster Intermediates in the Catalytic Mechanism of [FeFe]Hydrogenase CaI. J. Am. Chem. Soc. 2018, 140 (24), 7623-7628.

(123) Birrell, J. A.; Pelmenschikov, V.; Mishra, N.; Wang, H.; Yoda, Y.; Rauchfuss, T. B.; Cramer, S. P.; Lubitz, W.; Debeer, S. Spectroscopic and Computational Evidence That [ FeFe ] Hydrogenases Operate Exclusively with CO-Bridged Intermediates Spectroscopic and Computational Evidence That [ FeFe ] Hydrogenases Operate Exclusively with CO-Bridged. J. Am. Chem. Soc. 2020, 142 (1), 222-232.

(124) Lorent, C.; Katz, S.; Duan, J.; Julia Kulka, C.; Caserta, G.; Teutloff, C.; Yadav, S.; Apfel, U.-P.; Winkler, M.; Happe, T.; et al. Shedding Light on Proton and Electron Dynamics in [FeFe] Hydrogenases. J. Am. Chem. Soc. 2020, 142 (12), 5493-5497.

(125) Sidabras, J. W.; Duan, J.; Winkler, M.; Happe, T.; Hussein, R.; Zouni, A.; Suter, D.; Schnegg, A.; Lubitz, W.; Reijerse, E. J. Extending Electron Paramagnetic Resonance to Nanoliter Volume Protein Single Crystals Using a Self-Resonant Microhelix. Sci. $A d v .2019,5$ (10), eaay1394.

(126) Ash, P. A.; Carr, S. B.; Reeve, H. A.; Skorupskaite, A.; Rowbotham, J. S.; Shutt, R.; Frogley, M. D.; Evans, R. M.; Cinque, G.; Armstrong, F. A.; et al. Generating Single Metalloprotein Crystals in Well-Defined Redox States: Electrochemical Control Combined with Infrared Imaging of a NiFe Hydrogenase Crystal. Chem. Commun. 2017, 53 (43), 5858-5861.

(127) Hinokuma, S.; Wiker, G.; Suganuma, T.; Bansode, A.; Stoian, D.; Huertas, S. C.; Molina, S.; Shafir, A.; Rønning, M.; van Beek, W.; et al. Versatile IR Spectroscopy Combined with Synchrotron XAS-XRD: Chemical, Electronic, and Structural Insights during Thermal Treatment of MOF Materials. Eur. J. Inorg. Chem. 2018, 2018 (17), $1847-1853$.

(128) Mulder, D. W.; Ratzloff, M. W.; Shepard, E. M.; Byer, A. S.; Noone, S. M.; Peters, J. W.; Broderick, J. B.; King, P. W. EPR and FTIR Analysis of the Mechanism of H2 Activation by [FeFe]-Hydrogenase HydA1 from Chlamydomonas Reinhardtii. J. Am. Chem. Soc. 2013, 135 (18), 6921-6929.

(129) Bruschi, M.; Greco, C.; Kaukonen, M.; Fantucci, P.; Ryde, U.; De Gioia, L. Influence of the $[2 \mathrm{Fe}] \mathrm{H}$ Subcluster Environment on the Properties of Key Intermediates in the Catalytic Cycle of [FeFe] Hydrogenases: Hints for the Rational Design of Synthetic Catalysts. Angew. Chemie Int. Ed. 2009, 48 (19), 3503-3506.

(130) Zampella, G.; Fantucci, P.; De Gioia, L. Unveiling How Stereoelectronic Factors Affect Kinetics and Thermodynamics of Protonation Regiochemistry in [FeFe] Hydrogenase Synthetic Models: A DFT Investigation. J. Am. Chem. Soc. 2009, 131 (31), 10909-10917.

(131) Filippi, G.; Arrigoni, F.; Bertini, L.; De Gioia, L.; Zampella, G. DFT Dissection of the Reduction Step in $\mathrm{H} 2$ Catalytic Production by [FeFe]-Hydrogenase-Inspired Models: Can the Bridging Hydride Become More Reactive Than the Terminal Isomer? Inorg. Chem. 2015, 54 (19), 9529-9542.

(132) Haumann, M.; Stripp, S. T. The Molecular Proceedings of Biological Hydrogen Turnover. Acc. Chem. Res. 2018, 51 (8), 1755-1763.

(133) Chapman, H. N.; Caleman, C.; Timneanu, N. Diffraction before Destruction. Philos. Trans. R. Soc. B Biol. Sci. 2014, 369 (1647). 
(134) Pandey, S.; Bean, R.; Sato, T.; Poudyal, I.; Bielecki, J.; Cruz Villarreal, J.; Yefanov, O.; Mariani, V.; White, T. A.; Kupitz, C.; et al. Time-Resolved Serial Femtosecond Crystallography at the European XFEL. Nat. Methods 2020, 17 (1), 73-78.

(135) Fromme, P. XFELs Open a New Era in Structural Chemical Biology. Nat. Chem. Biol. 2015, 11 (12), 895-899.

(136) Armstrong, F. A.; Evans, R. M.; Hexter, S. V; Murphy, B. J.; Roessler, M. M.; Wul, P. Guiding Principles of Hydrogenase Catalysis Instigated and Clarified by Protein Film Electrochemistry. Acc. Chem. Res. 2016, 49 (5), $884-892$.

(137) Ash, P. A.; Reeve, H. A.; Quinson, J.; Hidalgo, R.; Zhu, T.; McPherson, I. J.; Chung, M. W.; Healy, A. J.; Nayak, S.; Lonsdale, T. H.; et al. Synchrotron-Based Infrared Microanalysis of Biological Redox Processes under Electrochemical Control. Anal. Chem. 2016, 88 (13), 6666-6671.

(138) Fourmond, V.; Wiedner, E. S.; Shaw, W. J.; Leger, C. On the Understanding and Design of Bidirectional and Reversible Catalysts Of. J. Am. Chem. Soc. 2019, 141 (28), 11269-11285.

(139) Sensi, M.; Baffert, C.; Greco, C.; Caserta, G.; Gauquelin, C.; Saujet, L.; Fontecave, M.; Roy, S.; Artero, V.; Soucaille, P.; et al. Reactivity of the Excited States of the HCluster of FeFe Hydrogenases. J. Am. Chem. Soc. 2016, 138 (41), 13612-13618.

(140) Sensi, M.; Baffert, C.; Fradale, L.; Gauquelin, C.; Soucaille, P.; Meynial-Salles, I.; Bottin, H.; De Gioia, L.; Bruschi, M.; Fourmond, V.; et al. Photoinhibition of FeFe Hydrogenase. ACS Catal. 2017, 7 (10), 7378-7387.

(141) Garczarek, F.; Gerwert, K. Functional Waters in Intraprotein Proton Transfer Monitored by FTIR Difference Spectroscopy. Nature 2006, 439, 216-219.

(142) Debus, R. J. FTIR Studies of Metal Ligands, Networks of Hydrogen Bonds, and Water Molecules near the Active Site Mn4CaO5 Cluster in Photosystem II. Biochim. Biophys. Acta - Bioenerg. 2015, 1847 (1), 19-34.

(143) Kottke, T.; Lórenz-Fonfría, V. A.; Heberle, J. The Grateful Infrared: Sequential Protein Structural Changes Resolved by Infrared Difference Spectroscopy. J. Phys. Chem. B 2017, 121, 335-350.

(144) Schultz, B.-J.; Mohrmann, H.; Lorenz-Fonfria, V. A.; Heberle, J. Protein Dynamics Observed by Tunable Mid-IR Quantum Cascade Lasers across the Time Range from 10 Ns to 1 S. Spectrochim. Acta - Part A Mol. Biomol. Spectrosc. 2017, 188, 666 674.

(145) Callender, R.; Dyer, R. B. Advances in Time-Resolved Approaches To Characterize the Dynamical Nature of Enzymatic Catalysis. Chem. Rev. 2006, 106, 3031-3042.

(146) Dyer, R. B.; Gai, F.; Woodruff, W. H.; Gilmanshin, R.; Callender, R. H. Infrared Studies of Fast Events in Protein Folding. Acc. Chem. Res. 1998, 31 (11), 709-716.

(147) Lübben, M.; Gerwert, K. Redox FTIR Difference Spectroscopy Using Caged Electrons Reveals Contributions of Carboxyl Groups to the Catalytic Mechanism of HaemCopper Oxidases. FEBS Lett. 1996, 397 (2-3), 303-307.

(148) Gutman, M.; Nachliel, E. Time-Resolved Dynamics of Proton Transfer in Proteinous Systems. Annu. Rev. Phys. Chem. 1997, 48 (1), 329-356. 
(149) Greene, B. L.; Vansuch, G. E.; Chica, B. C.; Adams, M. W. W.; Dyer, R. B. Applications of Photogating and Time Resolved Spectroscopy to Mechanistic Studies of Hydrogenases. Acc. Chem. Res. 2017, 50 (11), 2718-2726.

(150) Greene, B. L.; Wu, C. H.; McTernan, P. M.; Adams, M. W. W.; Dyer, R. B. ProtonCoupled Electron Transfer Dynamics in the Catalytic Mechanism of a [NiFe]Hydrogenase. J. Am. Chem. Soc. 2015, 137 (13), 4558-4566.

(151) Chica, B.; Wu, C. H.; Liu, Y.; Adams, M. W. W.; Lian, T.; Dyer, R. B. Balancing Electron Transfer Rate and Driving Force for Efficient Photocatalytic Hydrogen Production in $\mathrm{CdSe} / \mathrm{CdS}$ Nanorod-[NiFe] Hydrogenase Assemblies. Energy Environ. Sci. 2017, 10 (10), 2245-2255.

(152) Greene, B. L.; Wu, C.; Vansuch, G. E.; Adams, M. W. W.; Dyer, R. B. Proton Inventory and Dynamics in the $\mathrm{Ni}$ a $-\mathrm{S}$ to $\mathrm{Ni}$ a $-\mathrm{C}$ Transition of a [NiFe] Hydrogenase. Biochemistry 2016, 55 (12), 1813-1825.

(153) Mirmohades, M.; Adamska-Venkatesh, A.; Sommer, C.; Reijerse, E.; Lomoth, R.; Lubitz, W.; Hammarström, L. Following [FeFe] Hydrogenase Active Site Intermediates by Time- Resolved Mid-IR Spectroscopy. J. Phys. Chem. Lett. 2016, 7, 3290-3293.

(154) Ratzloff, M. W.; Wilker, M. B.; Mulder, D. W.; Lubner, C. E.; Hamby, H.; Brown, K. A.; Dukovic, G.; King, P. W. Activation Thermodynamics and H/D Kinetic Isotope Effect of the Hox to H RedH+ Transition in [FeFe] Hydrogenase. J. Am. Chem. Soc. 2017, No. Figure 2, jacs.7b04216.

(155) Greene, B. L.; Schut, G. J.; Adams, M. W. W.; Dyer, R. B. Pre-Steady-State Kinetics of Catalytic Intermediates of an [FeFe]-Hydrogenase. ACS Catal. 2017, 7, 2145-2150.

(156) Schut, G. J.; Adams, M. W. W. The Iron-Hydrogenase of Thermotoga Maritima Utilizes Ferredoxin and NADH Synergistically: A New Perspective on Anaerobic Hydrogen Production. J. Bacteriol. 2009, 191 (13), 4451-4457.

(157) Sanchez, M. L. K.; Sommer, C.; Reijerse, E.; Birrell, J. A.; Lubitz, W.; Dyer, R. B. Investigating the Kinetic Competency of CrHydA1 [FeFe] Hydrogenase Intermediate States via Time-Resolved Infrared Spectroscopy. J. Am. Chem. Soc. 2019, 141 (40), 16064-16070.

(158) Laun, K.; Baranova, I.; Duan, J.; Wittkamp, F.; Apfel, U.-P.; Happe, T.; Senger, M.; Stripp, S. T. Site-Selective Protonation of the Catalytic Cofactor in [FeFe]Hydrogenase. ChemRxiv 2019, 1-22.

(159) Reisner, E.; Powell, D. J.; Cavazza, C.; Fontecilla-Camps, J. C.; Armstrong, F. A. Visible Light-Driven H2 Production by Hydrogenases Attached to Dye-Sensitized TiO2 Nanoparticles. J. Am. Chem. Soc. 2009, 131 (51), 18457-18466.

(160) Elsden, S. R. Hydrogenase 1931-1981. Trends Biochem. Sci. 1981, 6 (9), 251-253.

(161) Horch, M.; Lauterbach, L.; Saggu, M.; Hildebrandt, P.; Lendzian, F.; Bittl, R.; Lenz, O.; Zebger, I. Probing the Active Site of an O2-Tolerant NAD+-Reducing [NiFe]Hydrogenase from Ralstonia Eutropha H16 by in Situ EPR and FTIR Spectroscopy. Angew. Chemie Int. Ed. 2010, 49 (43), 8026-8029.

(162) Wegelius, A.; Khanna, N.; Esmieu, C.; Barone, G. D.; Pinto, F.; Tamagnini, P.; Berggren, G.; Lindblad, P. Generation of a Functional, Semisynthetic [FeFe]- 
Hydrogenase in a Photosynthetic Microorganism. Energy Environ. Sci. 2018, 11 (11), 3163-3167.

(163) Mészáros, L. S.; Németh, B.; Esmieu, C.; Ceccaldi, P.; Berggren, G. In Vivo EPR Characterization of Semi-Synthetic [FeFe] Hydrogenases. Angew. Chemie - Int. Ed. 2018, 57 (10), 2596-2599.

(164) Kamp, C.; Silakov, A.; Winkler, M.; Reijerse, E. J.; Lubitz, W.; Happe, T. Isolation and First EPR Characterization of the [FeFe]-Hydrogenases from Green Algae. Biochim. Biophys. Acta 2008, 1777 (5), 410-416.

(165) Barstow, B.; Agapakis, C. M.; Boyle, P. M.; Grandl, G.; Silver, P. A.; Wintermute, E. H. A Synthetic System Links FeFe-Hydrogenases to Essential E. Coli Sulfur Metabolism. J. Biol. Eng. 2011, 5, 1-15.

(166) Poudel, S.; Tokmina-Lukaszewska, M.; Colman, D. R.; Refai, M.; Schut, G. J.; King, P. W.; Maness, P. C.; Adams, M. W. W.; Peters, J. W.; Bothner, B.; et al. Unification of [FeFe]-Hydrogenases into Three Structural and Functional Groups. Biochim. Biophys. Acta - Gen. Subj. 2016, 1860 (9), 1910-1921.

(167) Lichtman, J. W.; Conchello, J. A. Fluorescence Microscopy. Nat. Methods 2005, 2 (12), 910-919.

(168) Wencel, D.; Abel, T.; McDonagh, C. Optical Chemical PH Sensors. Anal. Chem. 2014, 86 (1), 15-29.

(169) Kos, P.; Plenio, H. A Fluorescent Molecular Probe for the Detection of Hydrogen Based on Oxidative Addition Reactions with Crabtree-Type Hydrogenation Catalysts. Angew. Chemie - Int. Ed. 2015, 54 (45), 13293-13296.

(170) Amrania, H.; Drummond, L.; Coombes, R. C.; Shousha, S.; Woodley-Barker, L.; Weir, K.; Hart, W.; Carter, I.; Phillips, C. C. New IR Imaging Modalities for Cancer Detection and for Intra-Cell Chemical Mapping with a Sub-Diffraction Mid-IR sSNOM. Faraday Discuss. 2016, 187, 539-553.

(171) Jin, M.; Lu, F.; Belkin, M. A. High-Sensitivity Infrared Vibrational Nanospectroscopy in Water. Light Sci. Appl. 2017, 6 (7), e17096.

(172) Amenabar, I.; Poly, S.; Goikoetxea, M.; Nuansing, W.; Lasch, P.; Hillenbrand, R. Hyperspectral Infrared Nanoimaging of Organic Samples Based on Fourier Transform Infrared Nanospectroscopy. Nat. Commun. 2017, 8, e14402.

(173) Kochan, K.; Perez-Guaita, D.; Pissang, J.; Jiang, J. H.; Peleg, A. Y.; McNaughton, D.; Heraud, P.; Wood, B. R. In Vivo Atomic Force Microscopy-Infrared Spectroscopy of Bacteria. J. R. Soc. Interface 2018, 15, e0115.

(174) Horch, M.; Schoknecht, J.; Wrathall, S. L. D.; Greetham, G. M.; Lenz, O.; Hunt, N. T. Understanding the Structure and Dynamics of Hydrogenases by Ultrafast and TwoDimensional Infrared Spectroscopy. Chem. Sci. 2019, 10 (39), 8981-8989.

(175) Adamson, H.; Robinson, M.; Bond, P. S.; Soboh, B.; Gillow, K.; Simonov, A. N.; Elton, D. M.; Bond, A. M.; Sawers, R. G.; Gavaghan, D. J.; et al. Analysis of HypD Disulfide Redox Chemistry via Optimization of Fourier Transformed Ac Voltammetric Data. Anal. Chem. 2017, 89 (3), 1565-1573. 
